\title{
Holozäne Landschaftsentwicklung an der Westküste der Nordseeinsel Amrum
}

\author{
Tanja Tillmann, Daniel Ziehe, Jürgen Wunderlich
}

How to cite: $\quad$ Tillmann, T., Ziene, D., Wunderlich J. (2013): Holozäne Landschaftsentwicklung an der Westküste der Nordsee Amrum. - E\&G Quaternary Science Journal, 62 (2): 98-119. DOI 10.3285/eg.62.2.02

Kurzfassung:

Barriereinseln und Außensände, geformt durch eine Kombination aus Wind, Wellen, Strömung und Küstenlängstransport gelten als morphologisch hoch aktive Küstenbereiche und variieren häufig in Ursprung, Genese und Entwicklung. Sie besitzen durch ihre dissipative Wirkungsweise eine bedeutende Schutzfunktion für rückwärtige Inseln, Halligen und Festlandbereiche und bilden vor der Küste Nordfrieslands die westliche Außengrenze des Wattenmeeres.

Ziel der nachfolgenden Studie ist es, anhand hochauflösender Georadarmessungen und sedimentologischer Daten aus Bohrungen die Landschaftsgeschichte an der Westküste Amrums sowie die Entstehung und interne sedimentäre Architektur des der Insel westlich angelagerten Kniepsandes zu untersuchen und die Prozesse, die zur Genese geführt haben, durch Datierungen zeitlich einzuordnen. Auf Grundlage der gewonnenen Daten wurden zwei stratigraphische Modelle entwickelt, welche die geologisch-geomorphologischen Prozesse und Sedimentationsbedingungen im Westküstenvorfeld erklären.

Ein Modell zeigt die Landschaftsentwicklung an der Westküste Amrums und beschreibt die Sedimentationsbedingungen, die im Vorfeld der Westküste herrschten, bevor der Kniepsand an die Insel heranwanderte. Auf der Landoberfläche des ertrinkenden saaleeiszeitlichen Geestkerns wurden zu Beginn der Flandrischen Transgression feinkörnige Sedimente eines Mischund Schlickwatts abgelagert. Es ist davon auszugehen, dass der damals noch weit vor der Küste Amrums liegende Kniepsand eine Barriere bildete und so an der heute hochenergetischen Westküste für strömungsberuhigte Sedimentationsbedingungen sorgte. Durch Erosion am Geestkern bildeten sich in unterschiedlichen Höhenpositionen fossile Kliffs, die dem damaligen Meeresspiegelstand entsprechen.

Ein weiteres Modell beschreibt den Andockmechanismus des Kniepsandes an die Insel Amrum. Durch die Anlagerung des ehemaligen Außensandes und den damit einhergehenden Sedimentinput wurden die Bedingungen für eine großflächige Dünenbildung geschaffen.

Holocene landscape development in front of the west coast of Amrum [North Sea/ German Bight] - Insights from groundpenetrating radar surveys and sedimentological data

Abstract:

Barrier sandbars and barrier islands are geologically young, highly dynamic and represent a complex coastal system that includes a number of different but closely related sedimentary depositional environments with geomorphologic elements of varying origin, genesis and evolution. Barrier sandbars are exposed ridges of sand that are built offshore by wave action.

The so-called Kniepsand on the island of Amrum represents one of the widest beaches in Europe. The Kniepsand originally belongs to a system of sandbars lining the North-Frisian coast. Some of these sandbars are already attached to the mainland (e.g. St. Peter-Ording-Sand and Westerhever-Sand). The offshore sandbars of Japsand, Norderoogsand and Süderoogsand are located in front of the western coastline of the North-Frisian Island and the Halligen and fulfil the function of natural coastal defence dissipating the energy of the incoming deep-water waves of the North Sea.

Barrier sandbars are usually investigated through the use of aerial photos and borehole data. Therefore, the processes of evolution, migration and the internal structure of sandbars are often unknown. That is why this study chooses an integrated approach using high-resolution ground-penetrating radar (GPR) and sedimentological analyses of shallow sediment cores drilled at selected sites along the radar profiles. A geophysical Survey Systems Inc. radar system, SIR-2000 coupled with a $200 \mathrm{MHz}$ antenna, was used.

Based on these data two sedimentary models were generated. One model describes the process of barrier sandbar migration and the attachment to the Pleistocene island core. According to historical maps and nautical charts of the sixteenth and seventeenth century, the Kniepsand used to be a solitary barrier sandbar located well in front of the island's west coast without any connection to its Pleistocene core consisting of Saalian moraine deposits. The presented model shows how the Kniepsand has welded onto the island core of Amrum.

Before the barrier sandbar was connected to the island, conditions for sedimentation had been quite different. Tidal flat deposits had been accumulated in a low energy environment. Tidal flat deposits show a general coarsening upward trend and turn into overlying coarser grained beach deposits. Old cliffs formed through several storm surges are also preserved in GPR data. The landscape evolution in front of the westcoast of Amrum was summarized in the second model.

Keywords: $\quad$ Holocene landscape development, barrier sandbar migration, barrier island stratigraphy, ground-penetrating radar (GPR), Amrum, North Sea/German Bight

Addresses of authors: T. Tillmann, Niedersächsisches Institut für historische Küstenforschung (NIhK), Viktoriastraße 26/28, 26382 Wilhelmshaven, E-Mail: tanja.tillmann@nihk.de; Carl von Ossietzky Universität Oldenburg, Institut für Chemie und Biologie des Meeres/ ICBM-Terramare, Schleusenstraße 1, 26382 Wilhelmshaven, E-Mail: tanja.tillmann@uni-oldenburg.de; D. Ziehe, Johann Heinrich von Thünen-Institut, Institut für Agrarrelevante Klimaforschung, Bundesallee 50, 38116 Braunschweig, E-Mail: daniel.ziehe@, vti.bund.de, J. Wunderlich, Goethe-Universität Frankfurt Institut für Physische Geographie, Altenhöferallee 1, 60438 Frankfurt, E-Mail: j.wunderlich@em.uni-frankfurt.de 


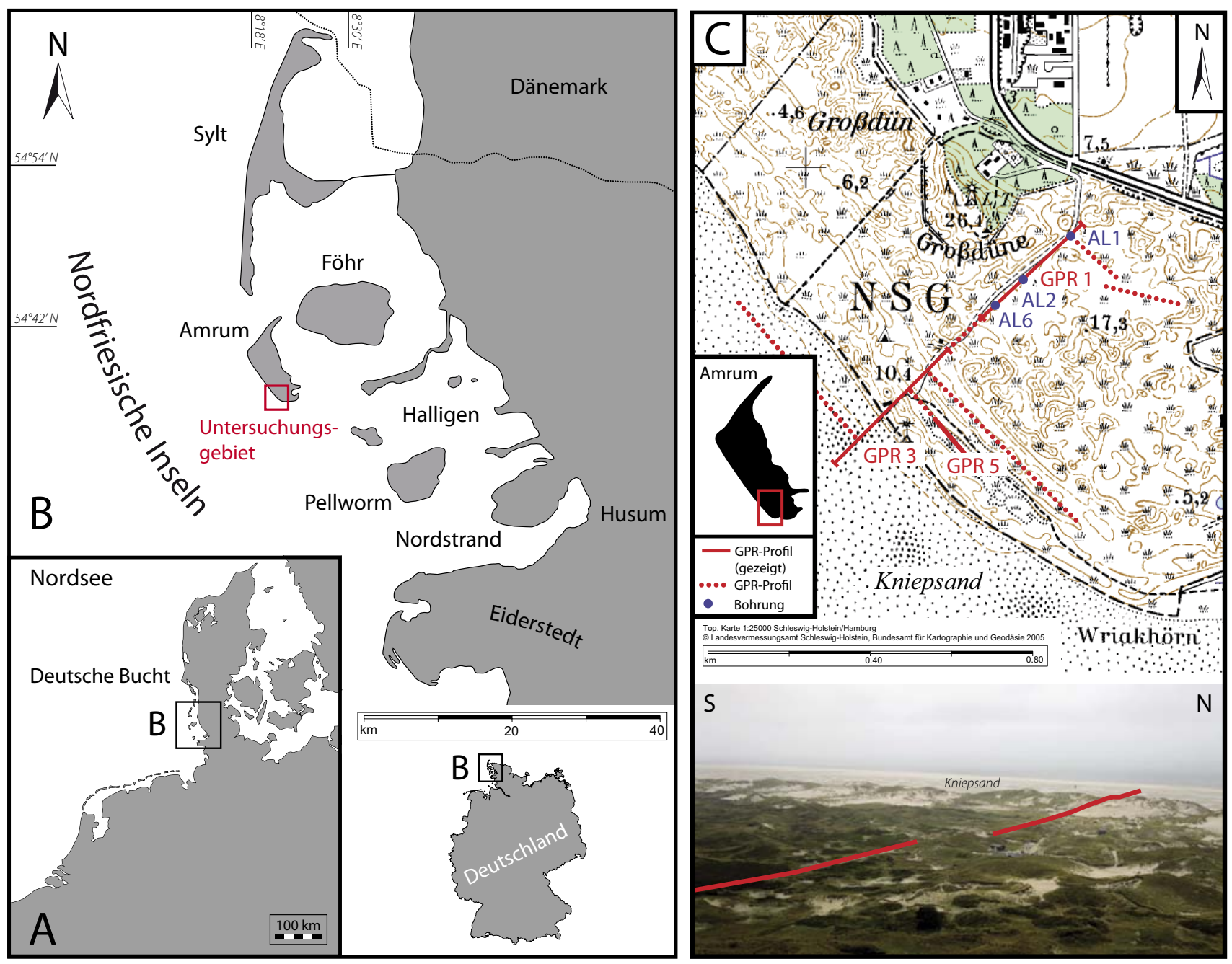

Abb. 1: Überblick über das Untersuchungsgebiet. A: Lage der Nordfriesischen Inseln innerhalb der Deutschen Bucht. B: Lage des Untersuchungsgebietes nahe des Leuchtturms der Insel Amrum. C: Position der GPR-Profile und Bohrungen im Untersuchungsgebiet.

Fig. 1: Overview of the study area. A: German Bight with the position of the Northfrisian Islands. B: Position of the study area next to the lighthouse of Amrum Island. C: Position of GPR-profiles and cores in the study area.

\section{Einleitung}

Barriereinseln und Außensände, geformt durch eine Kombination aus Wind, Wellen, Strömung und Küstenlängstransport gelten als morphologisch hoch aktive Küstenbereiche und variieren häufig in Ursprung, Genese und Entwicklung. Durch ihre dissipative Wirkungsweise besitzen sie eine bedeutende Schutzfunktion für die rückwärtigen Inseln, Halligen und Festlandbereiche und bilden so vor der Küste Nordfrieslands die Außengrenze des Wattenmeeres.

Bisherige Untersuchungen zur Stratigraphie dieser Sedimentationsräume basieren häufig allein auf Bohrungen. Daher sind die interne sedimentologische Struktur und die Prozesse, die zur Entwicklung und Wanderung von Barriereinseln und -sänden geführt haben, oftmals unzureichend untersucht.

Ziel der folgenden Studie ist es daher, anhand hochauflösender geophysikalischer und sedimentologischer Daten die Landschaftsgeschichte an der Westküste Amrums zu rekonstruieren sowie die interne sedimentäre Architektur des der Insel westlich angelagerten Kniepsandes zu untersuchen. Neben der Rekonstruktion der Landschaftsentwicklung sind vor allem die Sedimentationsbedingungen, die an der Westküste der Insel Amrum geherrscht haben, bevor sich der Kniepsand an die Insel anlagerte, von besonderem Interesse. Dabei stehen folgende Fragen im Vordergrund:

- Wie hat sich der Kniepsand als ehemaliger, weit vor der Westküste Amrums liegender Außensand, an die Insel anlagert?

- Welche Landschafts- und Sedimentationsbedingungen herrschten an der Westküste Amrums bevor der Kniepsand sich an die Insel anlagerte?

- Welche morphologischen Prozesse und Bedingungen haben zum Heranwandern und Andocken des ehemaligen Außensandes an den Inselgeestkern geführt?

- Inwieweit ist es möglich mit Hilfe hochauflösender Georadardaten die ursprüngliche Andockstelle des Kniepsandes an den Inselgeestkern zu definieren und rekonstruieren?

\section{Untersuchungsgebiet}

Die Insel Amrum in der südlichen Nordsee (Deutsche Bucht) bildet zusammen mit der nördlichen Nachbarinsel Sylt, den dänischen Inseln Fanø, Mandø, Rømø und den nordfriesischen Außensänden Japsand, Norderoog- und 

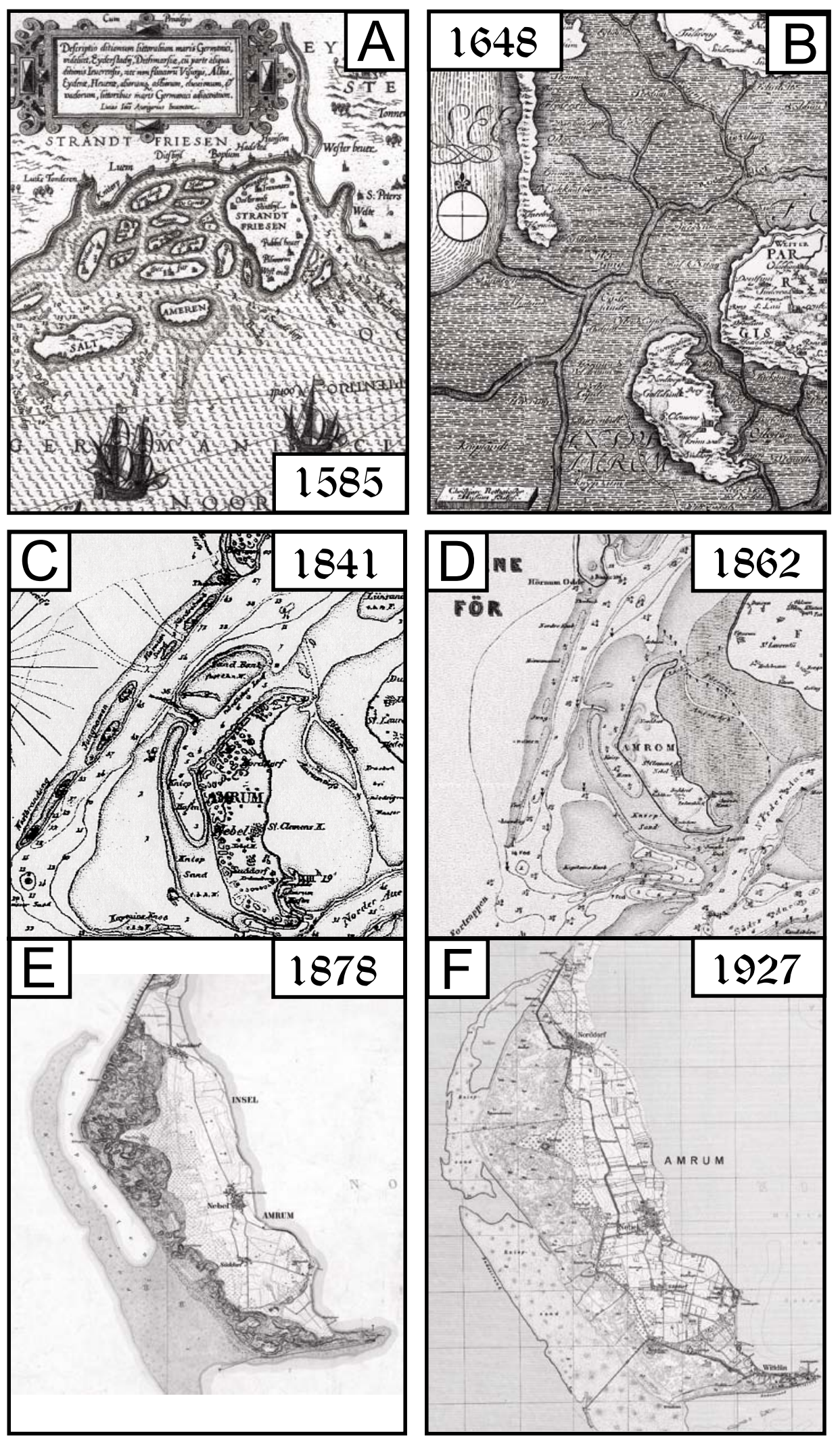

Abb. 2 A: Der Ausschnitt aus der Seekarte der Deutschen Bucht von W. F. Waghenaer aus dem fahr 1585 mit Blickrichtung nach Osten zeigt die Insel Amrum mit vorgelagerter Sandbank „Ameren Bor“. B: Ausschnitt aus der Landkarte des Amt Tondern aus dem Jahre 1648 nach Johannes Mejer verändert nach Danckwerth (1652). Westlich vor der Küste Amrum ist der „Kniepsandt" erstmals namentlich erwähnt. C: Ausschnitt aus einer Seekarte der Helgoländer Bucht von Zahrtmann aus dem fahre 1841(aus Lang 1973). D: Ausschnitt aus einer Seekarte der Helgoländer Bucht von Zahrtmann aus dem Jahre 1862 (aus Lang 1973). E: Ausschnitt aus einer topographischen Karte der Königl. Preuss. Landes-Aufnahme (Maßstab 1:25000) aus dem fahre 1878. F: Ausschnitt aus einer topographischen Karte (Meßtischb1att 199 im Maßstab 1:25000) aus dem fahre 1927.

Fig. 2 A: The map section of the German Bight of 1585 from W. F. Waghenaer shows the island of Amrum with the sandbar „Ameren Bor”. B: Map section of Tondern of 1648 from fohannes Mejer modified by Danckwerth (1652). The "Kniepsandt" is named to the west of Amrum's coast for the first time. C: Map section of the Helgoland Bight from Zahrtmann (1841) in Lang (1973). D: Map section of the Helgoland Bight from Zahrtmann (1862) in Lang (1973). E: Map section of a topographic map of the year 1878. F: Map section of a topographic map of the year 1927.

Süderoogsand im Süden eine Kette aus Barriereinseln, die als westliche Außengrenzen des Wattenmeeres der dänischen und schleswig-holsteinischen Festlandsküste vorgelagert sind. Von der Wortbedeutung leitet sich der Name Amrum von „Am Rem“ ab, das soviel bedeutet wie "sandiger Rand“ (QuedENs 2008) und sich morphologisch auf den der Insel Amrum im Westen vorgelagerten Kniepsand bezieht.

Geologisch gehört Amrum zu den Nordfriesischen Geestk- erninseln und weist als kleinste dieser Inseln eine Nord-SüdErstreckung von knapp $10 \mathrm{~km}$ und eine Fläche von rund $20 \mathrm{~km}^{2}$ auf. Wird der Kniepsand, ein heute bis zu $1,5 \mathrm{~km}$ breiter Sandstrand, der sich als ehemaliger Außensand entlang der Westküste erstreckt, mit zu der Inselfläche gerechnet, misst die Gesamtfläche $30,5 \mathrm{~km}^{2}$.

Das Untersuchungsgebiet befindet sich im Südwesten der Insel und umfasst das Dünengebiet südlich der 26,4 m ho- 
hen „Großdüne“ auf der 1875 der Leuchtturm (54³7'52,2” N/ $8^{\circ} 21^{\prime} 16,5^{\prime \prime}$ E) errichtet wurde (Abb. 1). An die Dünen schließt sich im Südwesten der Kniepsand an.

Der pleistozäne Geestkern der Insel Amrum nimmt heute mit 13,7 km2 etwa 2/3 der Inselfläche ein (REMDE 1972). Im Zuge der Flandrischen Transgression zu Beginn des Holozäns griff die Brandung des ansteigenden Meeresspiegels den Geestkern Amrums von allen Seiten an und schuf durch Abrasion an der gesamten Westküste und an vorspringenden Teilen der Ostküste ein Kliff. Auf diese Weise entstand an der Westküste Amrums auf einer Strecke zwischen Wriakhörn und Norddorf das Littorina Kliff. Im Gegensatz zum Steenodder Kliff an der Wattseite ist das Littorina Kliff an der Westküste rezent durch den Kniepsand und die vorgelagerten Dünenketten vor der Brandung geschützt und so zum fossilen Kliff geworden.

Eine Besonderheit hinsichtlich der Morphologie der Insel Amrum stellt der Kniepsand dar, der auf 16,5 km Länge entlang der Westküste von Wittdün im Süden bis nach Norddorf im Norden reicht. Mit bis zu $1,5 \mathrm{~km}$ Breite zählt er heute zu den breitesten Stränden Europas. Die rund 10 km2 große Sandfläche weißt im Mittel eine Höhe von $\mathrm{NN}+1,75 \mathrm{~m}$ auf und wird nur noch während winterlicher Sturmfluten vom Meer überflutet.

Aus geologischer Sicht ist der Kniepsand kein echter Bestandteil der Insel Amrum. Im weitesten Sinne handelt es sich um eine ehemalige der Westküste Amrums vorgelagerte Sandbank, die sich als einstiger Außensand der Inselküste im Westen angeschlossen hat. Der Kniepsand gehört damit zu einer Reihe von Außensänden und Sandbänken, die den Inseln und Halligen der Nordfriesischen Küsten im Westen vorgelagert sind. Einige dieser ehemaligen $\mathrm{Au}^{-}$ ßensände wie beispielsweise der Sand vor St. Peter-Ording und der weiter nördlich gelegene Westerhever-Sand sind bereits komplett an die Küste heran gewandert und stellen die heutigen Strände der dortigen Festlandsküste dar. Andere Außensände wie zum Beispiel der Norderoog- und Süderoogsand oder der deutlich kleinere Japsand westlich der Hallig Hooge liegen noch heute im offshore Bereich und dienen so den rückwärtigen Inseln und Halligen während Sturmfluten als natürlicher Wellenbrecher.

Einzelheiten hinsichtlich der Entstehung sowie der Herkunft des Kniepsandes sind bis dato nicht bekannt. Als erster verzeichnete ihn Mejer in seiner Karte aus dem Jahre 1648 (Abb. 2 Bild B), wo einige Kilometer westlich der Insel Amrum ein „Kniepsandt“ eingetragen ist. Dieser stellte vermutlich zu dieser Zeit für die Seefahrt eine Untiefe dar.

In historischen Seekarten aus dem 16. und 17. Jahrhundert, wie z. B. der Waghenaer-Karte aus dem Jahr 1585, ist der Kniepsand als solitäre Sandbank mit der Bezeichnung „Ameren bor“ (Amrumer Barriere) eingetragen (vgl. Abb. 2 A), die der Westküste von Amrum vorgelagert ist. Nach Hassenpflug (1985) lag der Kniepsand auch im 17. Jahrhundert noch als Außensand weit westlich der Insel und ist erst im Laufe der letzten Jahrhunderte von Westen an die Küstenlinie Amrums herangewandert. ZAusig (1939) stellte anhand alter Seekarten fest, dass der Kniepsand bei seiner Wanderung nach Osten einen alten Verlauf des HörnumTiefs zuschüttete, das damals zwischen dem Kniepsand und Amrum verlief. Der mittlere und südliche Teil der Sandbank lagerte sich zuerst an Amrums Westküste an.
So wird der Kniepsand in den Karten in den Abbildungen $2 \mathrm{C}$ bis $2 \mathrm{~F}$ als eine zu Amrum zählende Sandbank eingezeichnet, die auf der Höhe des Untersuchungsgebietes am Leuchtturm von Amrum bereits eine direkte Verbindung zum Inselkern aufweist. Deutlich erkennbar ist in den zwei Seekarten (Abb. 2 C und D) und in der topographischen Karte von 1878 (Abb. 2 E) der Kniephafen, der zu dieser Zeit einen beschiffbaren (REMde 1972; Quedens 2008) Hafen darstellte.

Das Andocken des Kniepsandes an die Insel erfolgte morphologisch als Sandbank. Nach der Anlagerung des einstigen Außensandes erfuhr der Kniepsand allmählich eine Modifikation, die primär durch eine nach Norden und Süden gerichtete Strömungskomponente des Küstenlängstransportes gesteuert wurde. Die Art und Weise seiner Weiterentwicklung charakterisieren den heutigen Kniepsand dementsprechend als Ablagerung einer Meeresströmung und somit eindeutig als Nehrungsbildung. Bereits JoHANNSEN (1867) zitiert nach MüLLER \& FISCHER (1937: 93) wies auf diese morphologische Veränderung hin und schrieb über den Kniepsand „[...] diese zwei Stunden lange Sandbank verlängert sich nach Süden wie nach Norden und wird nur bei Springflut und außerordentlichen Sturmfluten überschwemmt“.

Die Wurzel der Nehrung bzw. ihr Aufhängerpunkt an der Küste ist nach Voigt (1969) westlich des Amrumer Leuchtturms zu suchen. Von seiner ursprünglichen Ansatzzone aus schob sich der Kniepsand dementsprechend nach Nordwesten vor. Durch eine nach Norden gerichtete Meeresströmung wuchs der Nehrungsstreifen allmählich von seinem Wurzelgebiet am Wriakhörn südlich des Leuchtturms zunächst nach Nordwesten und später nach Norden (VoIgT 1969). Der nördliche Teil bewegte sich langsamer, sodass eine Bucht mit Nehrungscharakter und Lagune entstand in der sich bis 1890 (Quedens 2008) der Kniephafen befand. Dieser stellte in historischer Vergangenheit einen wichtigen Ankerplatz für Fischer- und Segelboote dar (JEsSEN 1932) und reichte in seiner äußersten Ausdehnung bis westlich der Satteldüne. Reste der ehemaligen Bucht waren noch 1913 zu erkennen (KraUse 1913) und sind in der Karte von 1927 (Abb. 2 E) nördlich des Quermarkenfeuers abgebildet. Der Kniephafen verlandete allmählich von Süden her und wurde im Norden von dem langsam nachrückenden Teil des Kniepsandes geschlossen (REMDE 1972).

Gemäß JohANNSEN (1861) war der Kniepsandhafen bereits um das Jahr 1860 nicht mehr für Lastensegler schiffbar. Nach Krause (1913) lagerte sich der Kniepsand zuerst in seiner Mitte an den Inselkörper an, sodass infolge seiner West-Ost-Wanderung die Strömung in dem parallel zur Küstenlinie verlaufenden Priel „Troode diep“ (VoIGT 1969) unterbrochen und Stillwasserbereiche für die Akkumulation feinkörniger Sedimente geschaffen wurden. ZAUsig (1939) vermutete ferner, dass der nördliche Teil von einem anstehenden festeren Untergrund in seiner Wanderungsbewegung verlangsamt wurde. Dieser festere Untergrund ist in den historischen Karten als „Sylter Riff“ eingetragen. Heute hat der Kniepsand sich vollständig an die Westküste von Amrum angeschlossen und den ehemaligen Kniephafen mitsamt der Bucht zugeschüttet.

Demzufolge setzt sich der heutige Kniepsand morphologisch aus zwei ihrer Entstehung nach verschiedenen Tei- 
len zusammen, nämlich der eigentlichen Nehrung und dem Kniephafen, den man als das zum Nehrungsstreifen gehörende Haff bezeichnen kann (VoIGT 1969).

\section{Methoden}

Im Untersuchungsgebiet Amrumer Leuchtturm wurde eine Methodenkombination aus Georadarmessungen, Bohrungen, sedimentologischen Laboranalysen und AAR-Datierungen angewandt.

\subsection{Georadar [GPR]}

Das Georadar, engl. Ground-penetrating radar (GPR), ist ein hochauflösendes elektromagnetisches Impulsreflexionsverfahren, das eine hochauflösende und zerstörungsfreie Prospektion des oberflächennahen Untergrundes bietet (vgl. u. a. AnNAn 2001, 2009; Blindow et al. 2005). Elektromagnetische Wellen breiten sich im Untergrund aus und werden bei Änderungen elektrischer Materialeigenschaften reflektiert, gebrochen, gestreut und zum Teil absorbiert. Das reflektierte elektrische Feld der elektromagnetischen Welle wird aufgezeichnet und in einem Weg-Zeit-Diagramm, dem Radargramm, dargestellt. Durch die Reflexion an Schichtgrenzen oder Störkörpern erhält man ein quasi kontinuierliches Profil des Untergrundes in Abhängigkeit von dessen dielektrischen Eigenschaften (ANNAN 2009).

Die nachfolgenden Georadarmessungen wurden mit einem Georadarsystem SIR 2000 der Firma Geophysical Survey Systems Inc. (GSSI SIR-2000) in Kombination mit einer $200 \mathrm{MHz}$ Antenne durchgeführt. Insgesamt wurden im Untersuchungsgebiet am Leuchtturm von Amrum 8 GPR-Profile auf natürlichem Untergrund gemessen (Abb. 1). Für die Georadarmessungen wurde ein 2-dimensionales und 2,5-dimensionales Survey Design gewählt. Eine 2,5 dimensionale Darstellung wird durch Kreuzungs- oder Berührungspunkte einzelner zweidimensionaler GPR-Profile gewährleistest und ermöglicht so eine pseudo-dreidimensionale Betrachtungsweise der Untergrundstrukturen im Arbeitsgebiet. Die Messungen erfolgten parallel und senkrecht zur heutigen Küstenlinie.

Die Transekte der GPR-Profile wurden bevorzugt auf ebenem Gelände und in den flachen Bereichen der Dünentäler gemessen. Dennoch führen auch schon geringe topographische Höhenunterschiede entlang der Georadar-Transekte zu Verzerrungen im Radargramm (z. B. FISHER et al. 1996; JoL ঔ Bristow 2003; TILlMANN \& Wunderlich 2012) und wurden daher im unmittelbaren Anschluss an die Georadarmessungen mit Hilfe eines differentiellen GPS Systems (Ashtech ProMark 2) erfasst. Die Ausbreitungsgeschwindigkeiten der elektromagnetischen Welle im Untergrund wurden mit Hilfe von Diffraktionshyperbeln und durch die Korrelation mit Bohrungen ermittelt.

Das Processing der GPR-Rohdaten erfolgte mit der Software „Reflex-Win“ (Version 5.6) der Firma „Sandmeier Scientific Software, Karlsruhe“. So wurde ein Bearbeitungsverfahren aus offset-Korrektur, dewow-Filter, Bandpassfilter und background removal-Filter standardmäßig angewendet.

Eine mit zunehmender Tiefe verstärkte Signalabschwächung konnte mit Hilfe der gain-Funktion (energy decay) kompensiert werden. Die Migration der Radargramme erfolgte unter Verwendung des Migrations-Algorithmus nach Stolt (1978). Jedem einzelnen GPR-Profil wurde dabei eine einheitliche Durchschnittsgeschwindigkeit zugrunde gelegt. Durch die Migration wurden die Achsen von Diffraktionshyperbeln entfernt und die Reflexionen der Objekte auf einen punktförmigen Reflektor reduziert, der der tatsächlichen Objektlage und -größe entspricht. Wo Diffraktionshyperbeln im starken Maße zur Interpretation beitragen, wurde auf das Entfernen der Hyperbeln im Radargramm verzichtet.

\subsection{Bohrungen und sedimentologische Laboranalysen}

Im Untersuchungsgebiet am Leuchtturm von Amrum wurden Rammkern- und Pürkhauersondierungen durchgeführt. Die Rammkernsondierungen AL2 und AL6 sowie die Pürkhauersondierung AL1 wurden direkt in das Transsekt von GPR-Profil 1 eingebracht. Die Rammkernsondierungen AL2 und AL6 wurden mit einer Kombination aus Benzinschlagkopfbohrer (Wackerbohrer), Schlitzsonden und hydraulischem Ziehgerät durchgeführt und bis zu einer Tiefe von $8 \mathrm{~m}$ abgeteuft. In Abhängigkeit von der Eindringteufe kamen unterschiedliche, sich mit zunehmender Tiefe verjüngende Schlitzsonden $(\varnothing=80 \mathrm{~mm}, \varnothing=60 \mathrm{~mm}, \varnothing=30$ $\mathrm{mm})$, zum Einsatz.

Aus den Bohrkernen wurden ca. 90 Sedimentproben für granulometrische Laboranalysen (Nass- und Trockensiebung) entnommen. Zur Berechnung korngrößenstatistischer Parameter wurde das Programm Gradistat nach Blotт \& Pye (2001) verwendet. Die Auswertung nach korngrößenstatistischen Parametern erfolgte mit der Methode nach FolK \& WARD (1957).

\subsection{Datierung}

Für die Datierung der Probe aus dem Untersuchungsgebiet Amrum Leuchtturm wurde die Aminosäure-Racemisierungs-Methode (AAR) herangezogen.

Die AAR-Datierung wurde im Jahre 2012 von Herrn Dr. Daniel Ziehe im Johann Heinrich von Thünen-Institut in Braunschweig durch die in ZIEHE (2009) entwickelte Methode durchgeführt.

Die AAR-Datierung beruht auf der Bestimmung von Aminosäure-D/L-Verhältnissen in den organischen Matrices biogener Carbonate (vgl. DEMARChI et al. 2011; GooDFriend 1987; Murray-Wallace \& Belperio 1994; Ziehe 2009). Die Anwendbarkeit der AAR-Methode für geologisch sehr junge Ablagerungsräume wurde von ZIEHE (2009) am Beispiel unterschiedlicher Standorte im Wattenmeer nachgewiesen.

Zur Datierung wurde eine Herzmuschel (Cerastoderma edule) herangezogen, die als intakte Schalenklappe aus einer Bohrtiefe von $728 \mathrm{~cm}$ gewonnen wurde. Aufgrund ihrer Einbettung in schillfreie, feinkörnige Wattsedimente ist davon auszugehen, dass es sich um den ursprünglichen Lebensraum der Muschel handelt, bzw. diese nicht in Form von Bruchschill verlagert wurde. Um etwaige Messungenauigkeiten zu minimieren, wurde die Probe 3-fach datiert. Aus abweichenden Messergebnissen wurde anschließend ein Mittelwert gebildet. Die zeitliche Einordnung mittels der AAR-Methode ist aufgrund der geringen Datendichte an datierbarem Mate- 


\begin{tabular}{|c|c|c|c|c|c|c|}
\hline Radargramm & Interpretation & $\begin{array}{l}\text { Radar- } \\
\text { fazies }\end{array}$ & $\begin{array}{l}\text { Ampli- } \\
\text { tude }\end{array}$ & $\begin{array}{l}\text { Form, Winkel, } \\
\text { Kontinuität, } \\
\text { Besonderheiten }\end{array}$ & $\begin{array}{l}\text { Position, } \\
\text { Tiefe }\end{array}$ & $\begin{array}{l}\text { Sedimentologische } \\
\text { Interpretation }\end{array}$ \\
\hline $\begin{array}{l}\text { A. Einfallen } \\
20 \mathrm{~m} \\
\end{array}$ & $\begin{array}{l}\text { Reflexionen } \\
20 \mathrm{~m} \\
\end{array}$ & Rf-AL-A1 & $\begin{array}{l}\text { stark - } \\
\text { mittel }\end{array}$ & $\begin{array}{l}\text { kontinuierlich, } \\
\text { subparallel - parallel }\end{array}$ & $\begin{array}{l}\text { vorwiegend } \\
\text { oberhalb } \\
\text { von Rf-AL-B1 }\end{array}$ & $\begin{array}{l}\text { Dünen-Fazies, } \\
\text { äolische Kreuz- und } \\
\text { Schrägschichtung }\end{array}$ \\
\hline $35 \mathrm{~m}$ & -1 & Rf-AL-A2 & mittel & $\begin{array}{l}\text { wellen- bis rinnenförmige } \\
\text { konkave + konvexe } \\
\text { Reflexionen, einzelne } \\
\text { Diffraktionshyperbeln, } \\
\text { mäßig kontinuierlich }\end{array}$ & $\begin{array}{l}\text { im Bereich } \\
\text { von Rf-AL-B1 } \\
\text { bis unter } \\
\text { Rf-AL-B1 }\end{array}$ & $\begin{array}{l}\text { intertidale Sedimentkörper/ } \\
\text { swash bars und ridge-and- } \\
\text { runnel-Topographie auf dem } \\
\text { Strand }\end{array}$ \\
\hline $30 \mathrm{~m}$ & $30 \mathrm{~m}$ & Rf-AL-A3 & $\begin{array}{l}\text { stark - } \\
\text { mittel }\end{array}$ & $\begin{array}{l}\text { sigmoidal - oblique tangential, } \\
\text { kontinuierlich - mäßig } \\
\text { kontinuierlich }\end{array}$ & $\begin{array}{l}\text { ausschließlich } \\
\text { unter } \\
\text { Rf-AL-B1 }\end{array}$ & $\begin{array}{l}\text { Progradations-Fazies/ } \\
\text { Kniepsand }\end{array}$ \\
\hline
\end{tabular}

B. Horizontale Reflexionen
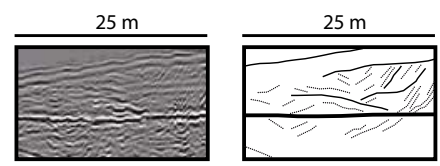

Rf-AL-B1 stark planar kontinuierlich,

horizontal - subhorizontal,

Grundwasserspiegel

$25 \mathrm{~m}$

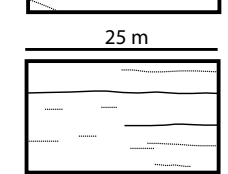

linear

Rf-AL-B2 mittel- horizontal - planar, schwach parallel, mäßig kontinuierlich

- diskontinuierlich

ausschließlich

Watt-Fazies

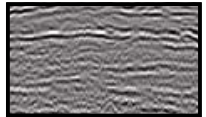

$30 \mathrm{~m}$

$30 \mathrm{~m}$
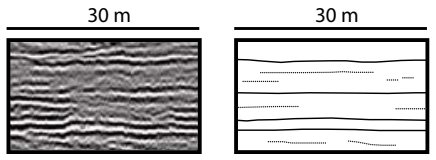

Rf-AL-B3

mittel -

horizontal, planar,

von Rf-AL-B1

parallel - subparallel,

kontinuierlich -

mäßig kontinuierlich

C. Irreguläre Reflexionen
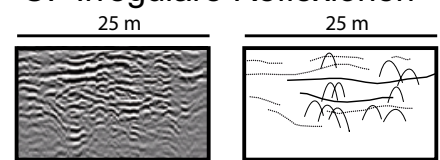

$25 \mathrm{~m}$
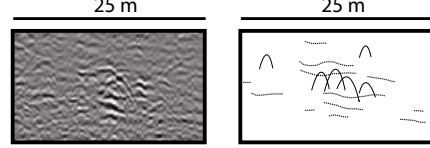

Rf-AL-C1 stark - mäßig kontinuierlich, mittel wellenförmig, teilweise

chaotisch, viele

Diffraktionshyperbeln

Rf-AL-C2 schwach diskontinuierlich, chaotisch, Diffraktionshyperbeln unter

Rf-AL-B1

Geschiebenester

im Geestkern

vorwiegend

unter

Rf-AL-B1

Geestkern-Fazies

D. Radar-Schichtflächen

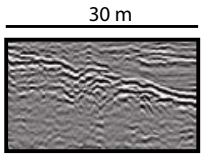

$40 \mathrm{~m}$

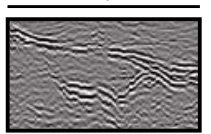

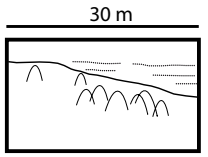

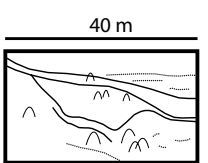

Rf-AL-D1 stark

nach Westen einfallende

Schichtfläche mit

Diffraktionshyperbeln

kontinuierlich

Rf-AL-D2 stark steil einfallende Schicht-

flächenkonfiguration,

Diffraktionshyperbeln,

kontinuierlich größtenteils Geestkernoberfläche,

unter Grenze zwischen

Rf-AL-B1 Watt/ Strand und Geestkern

coastal onlap

unter

Rf-AL-B1

fossile Kliffs entstanden

durch sturmflutbedingte

Erosion am Geestkern,

Brandungshohlkehlen

Abb. 3: Radarfazies-Definition aus dem Untersuchungsgebiet Amrum Leuchtturm.

Fig. 3: Radarfacies-definition of the study area next to the lighthouse of Amrum. 
rial sowie dem Fehlen von Vergleichsaltern lediglich als grober zeitlicher Anhaltspunkt zu sehen.

\section{Ergebnisse}

\subsection{Radarfazies Analyse}

Reflexionsmuster in GPR-Daten lassen auf Sedimentstrukturen im Untergrund schließen. Die Interpretation der gezeigten GPR-Profile basiert auf der Methode der Radarstratigraphie. Die Radarstratigraphie wurde erstmals durch JoL \& SMITH (1991) als eine Interpretationstechnik für Georadardaten eingeführt und basiert in ihren Grundzügen auf den Prinzipien der in den 1970er Jahren von der Erdölindustrie entwickelten Seismischen Stratigraphie nach Miтchum et al. (1977). Diese geht von sedimentären Sequenzen (speziell siliziklastischen Sequenzen) aus, die in eine Hierarchie der Sedimentationseinheiten von einzelnen Laminae bis hin zu sedimentären Beckenfüllungen unterteilt werden (Allen 1982; CAMPBEll 1967; Miall 1991) und stellt damit die Grundlage der Sequenzstratigraphie dar (PAyton 1977). Durch die Definition einer Radarfazies werden die Reflexionsmuster des Untersuchungsgebietes klassifiziert und entsprechend einer von NEAL (2004) entwickelten Standardterminologie zusammengefasst. Auf diese Weise ist es möglich, die Radargramme in ihre stratigraphischen Einheiten zu unterteilen, und so in eine relative chronologische Reihenfolge einzuordnen. Im Untersuchungsgebiet am Leuchtturm von Amrum ließen sich insgesamt 10 unterschiedliche Radarfazien definieren. Die Benennung der Radarfazies erfolgte nach folgendem Schema. Eine erste Einteilung der Reflexionen erfolgte in Bezug auf das Untersuchungsgebiet und wird mit „AL“ für „Amrum Leuchtturm“ abgekürzt. Des Weiteren wird zwischen einfallende Reflexionen (Rf-AL-A), horizontale Reflexionen (Rf-AL-B), irreguläre Reflexionen (Rf-AL-C) und Radarschichtflächen (Rf-AL-D) unterschieden (Abb. 3).

\section{$R f-A L-A 1$ Dünen-Fazies \\ Radarfazies}

Die Radarfazies Rf-AL-A1 umfasst einfallende kontinuierliche bis moderat kontinuierliche Reflektoren von mittlerer bis starker Amplitude (vgl. auch TILLMANN \& WUNDERLICH 2011a, 2011b, 2013). Die einzelnen Reflektoren sind zueinander parallel bis subparallel orientiert und besitzen ein steiles bis mittleres Einfallen $\left(10^{\circ}-30^{\circ}\right)$ in unterschiedliche Richtungen. Die Reflexionen sind in einzelne Radarschichtpakete unterteilt.

\section{Sedimentfazies}

In den Bohrkernen AL1, AL2 und AL6 besteht Rf-AL-A1 ausschließlich aus hellen Fein- und Mittelsanden. Die mittlere Korngröße bewegt sich im feinen Mittelsandbereich zwischen 2,11 $\varphi$ und 1,73 $\varphi$. Die Sedimente von Rf-AL-A1 weisen eine mäßig gute $(0,60 \varphi)$ bis mäßige Sortierung $(0,81$ $\varphi)$ auf und zeigen dadurch nur geringe Abweichung innerhalb des Korngrößenspektrums.

Die Korngrößenverteilung von Rf-AL-A1 ist in der Regel unimodal bis bimodal mit dem größten Anteil an der Korngröße Mittelsand. Die Schiefe ist dementsprechend vorwiegend symmetrisch $(0,067 \quad \varphi$ bis
$-0,002 \varphi$ ). Geringfügige Abweichungen zu einer positiven und negativen Schiefe sind dennoch festzustellen und abhängig davon, ob innerhalb der Sedimentprobe von Rf-ALA1 gröbere oder feinere Mittelsande dominieren.

Die Sedimente von Rf-AL-A1 enthalten im Bohrkern keine makroskopisch erkennbaren Muscheln oder Schillanteile. Grobe Komponenten wie Kiese sind ebenfalls nicht nachzuweisen. Demgegenüber sind Wurzeln in Verbindung mit organischen Humushorizonten häufig.

\section{Interpretation}

Die Radarfazies Rf-AL-A1 wird als Dünen-Fazies interpretiert. Eine vergleichbare Radarfazies-Definition ist bereits aus früheren Arbeiten (z. B. BRISTOw et al. 1996, 2000a, 2000b, 2010a, 2010b; BothA et al. 2003; GIRARDI \& DAVIS 2010; HARARI 1996; TillmanN \& Wunderlich 2012, 2013) bekannt. Im Untersuchungsgebiet bildet die Dünen-Fazies die jüngste stratigraphische Einheit und zeigt im Radargramm (Abb. 4) die für Küstendünen typischen äolischen Sedimentstrukturen der Schräg- und Kreuzschichtung, die durch kleinräumig wechselnde Windrichtungen bedingt sind (MCKeE 1966; TuCKer 1985; VAN OverMEEREN 1998).

Die interne Dünenschichtung setzt sich aus einzelnen sog. „foresets“ zusammen und ist von als „bounding surfaces“ (vgl. Bristow 2009; BRISTOW \& PUCILlo 2006) bezeichneten Schichtflächen unterbrochen. Generell resultiert die interne Struktur und Schichtung von Dünen aus Änderungen des vorherrschenden Windregimes bzw. einer dadurch bedingten Wanderungsbewegung (DAvis 1992).

Ein Beispiel für die komplexe interne Geometrie der Dünen im Untersuchungsgebiet am Leuchtturm von Amrum zeigt die Vordüne aus GPR-Profil 5 in Abbildung 4. Das 130 m lange GPR-Transekt wurde im Weißdünengürtel parallel zur Küste mittels einer $200 \mathrm{MHz}$-Antenne gemessen und verläuft von Nordwesten nach Südosten. Der als Sedimentlieferant fungierende Strand (Kniepsand) befindet sich südwestlich der Vordünenkette. Die Düne zeigt zahlreiche einzelne foresets-Schichten, die in Sedimentpakete von bis $\mathrm{zu} 2 \mathrm{~m}$ Mächtigkeit zusammengefasst und durch zahlreiche bounding surfaces begrenzt werden. Unterschiedliche Einfallswinkel und Richtungen der bounding surfaces lassen kleinräumig wechselnde Windbedingungen vermuten. Diffraktionshyperbeln innerhalb des Dünenkomplexes und an den Oberflächen der bounding surface sind häufig und werden in Übereinstimmung mit Beiträgen von GIRADI \& DAvis (2010) und VAN DAM (2012) als durch Dünensand überdeckte Vegetation (evtl. Strandhaferhorste) interpretiert.

Abbildung 4 (Bild D) zeigt einen Ausschnitt der internen Dünenschichtung im Kern einer in das GPR-Transekt eingebrachten Pürkhauersondierung. Die mittleren Korngrößen bewegen sich zwischen 1,092 $\varphi$ und 1,719 $\varphi$. Demzufolge entsprechen alle Schichten Sanden der Mittelsandfraktion und zeigen somit nur geringe Variationen hinsichtlich der Korngröße.

Dennoch können schon minimale Änderungen von Korngröße und Kornzusammensetzung der Dünensande Änderungen im Wasserhaushalt der einzelnen Schichten hervorrufen und dadurch im Radargramm zu Reflexionen führen. Auch organische Boden- und Wurzelhorizon- 


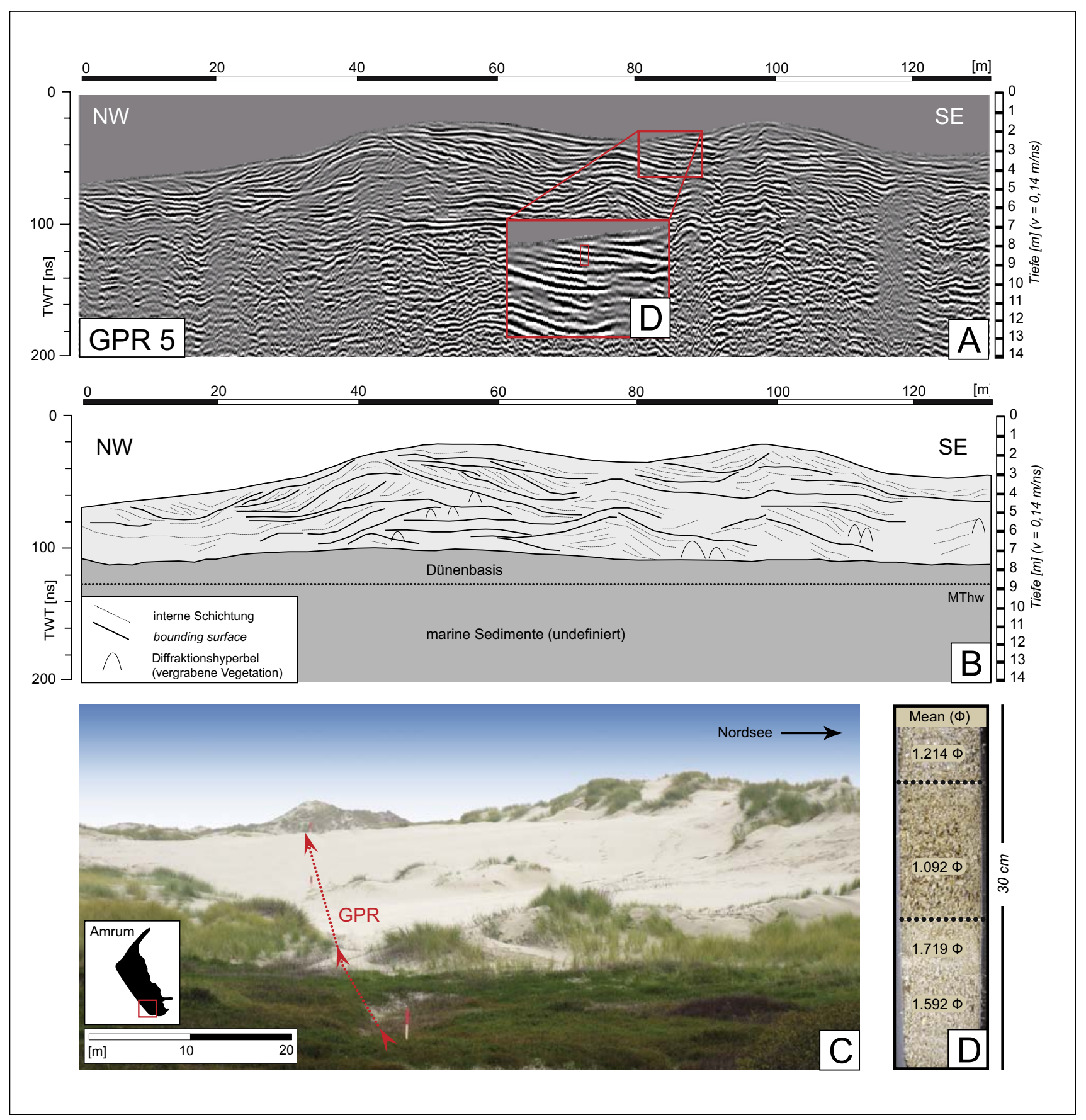

Abb. 4 A: Das Radargramm (200 MHz) zeigt einen Ausschnitt aus GPR-Profil 5. Die Lage von GPR-Profil 5 im Untersuchungsgebiet ist aus Abbildung 1 ersichtlich. Für die GPR-Daten wurde ein Basis-Processing aus (static correction, subtract-mean dewow, Bandpassfilter, background removal, gain) angewandt und die Topographie mit Hilfe von dGPS Koordinaten ausgeglichen. Für die trockenen Dünensande wurde eine Durchschnittsgeschwindigkeit von 0,14 m/ ns ermittelt. B: Interpretation und Legende. Bounding surfaces sind durch starke Linien gekennzeichnet. Die interne Schichtung ist anhand feiner Linien zu erkennen. C: Foto der Düne mit Lage von GPR-Profil 5. D: Pürkhauer-Bohrung und Korngrößenverteilung innerhalb der Dünen-Fazies.

Fig. 4 A: The radargramm (200 MHz) shows a section of GPR-profile 5. Position of GPR-profile 5 in the study area is shown in figure 1. Processing (static correction, subtract-mean dewow, bandpassfilter, background removal, gain) and topographic correction of the radargramm were already applied. A velocity of $0.14 \mathrm{~m} / \mathrm{ns}$ was determined for dry dune sand. B: Interpretation and legend. Bold lines represent bounding surfaces, fine lines display internal structures. C: Picture of the dune with position of GPR-profile 5. D: Core and grain size characteristic of the dune facies.

te konnten innerhalb der Dünenschichtung nachgewiesen werden. Sie verursachen im Radargramm ebenfalls verstärkte Reflexionen.

\section{Rf-AL-A2 intertidale Sedimentkörper (swash bars) Radarfazies}

Die Reflexionen der Radarfazies Rf-AL-A2 kommen im Radargramm im direkten Verbund mit den Reflexionen der Radarfazies Rf-AL-B3 vor und umfassen den Tiefenbereich von $0 \mathrm{~m}$ NN bis $-4 \mathrm{~m} \mathrm{NN}$. Dementsprechend ist Rf-AL-A2 ausschließlich unterhalb des Grundwasserspiegels nachzuweisen.

Im Radargramm bilden die Reflexionen von Rf-AL-A2 sowohl konkave, rinnenförmige Hohlformen als auch konvexe Vollformen aus. Hohlformen und Vollformen kommen in unmittelbarer Nachbarschaft zueinander vor und lassen auf einen morphologischen Zusammenhang schließen. Gelegentlich sind innerhalb der Radarfazies von Rf-AL-A2 ein- 
zelne Diffraktionshyperbeln festzustellen, die allerdings kein eindeutiges Verteilungsmuster aufweisen.

\section{Sedimentfazies}

Hinsichtlich der Sedimentfazies bestehen keine oder nur geringfügige Unterschiede von Rf-AL-A2 und Rf-AL-B3. Dies deutet auf einen morphologischen Zusammenhang oder einen einheitlichen Sedimentationsraum hin. So dominieren schillführende Fein- und Mittelsande $(1,00 \varphi-2,13 \varphi)$, die eine mäßige bis mäßig gute $(0,60 \varphi-0,97 \varphi)$ Sortierung aufweisen. Die Korngrößen sind vorwiegend unimodal und bimodal verteilt, besitzen eine beinahe symmetrische Schiefe und zeigen daher nur geringfügige Abweichungen.

\section{Interpretation}

Der direkte Verbund der Reflexionen von Rf-AL-A2 und RfAL-B3 im Radargramm deutet auf einen einheitlichen Sedimentationsraum sowie eine ähnliche Genese der durch Rf-AL-A2 und Rf-AL-B3 abgebildeten Sedimentstrukturen hin. Geomorphologisch handelt es sich bei den Radarfazien Rf-AL-A2 und Rf-AL-B3 um einen Strand, der den Tiefenbereich von $0-4 \mathrm{~m}$ unter $\mathrm{NN}$ umfasst.

Im Vergleich $\mathrm{zu}$ horizontal lagernden und in der Regel gut geschichteten Wattsedimenten bilden die als Strandsedimente interpretierten Reflexionen von Rf-AL-A2 und Rf-AL-B3 eine typisch unruhige Strandmorphologie aus. Primär wird diese durch die Radarfazies Rf-AL-A2 hervorgerufen, die aufgrund ihrer Reflexionsgeometrien sedimentologisch auf Voll- und Hohlformen hindeutet.

Der interne Aufbau der Vollformen ähnelt dabei der internen Schichtung intertidaler Sedimentkörper (tidal bars, swash bars) wie sie heute im Strandbereich vieler Nordseeinseln zu finden sind. Intertidale Sedimentkörper (intertidal bars und swash bars) zählen nach FITzGERALD (2005) zu den typischen Elementen der Strandmorphologie im foreshore-Bereich. Die sog. swash bars zeigen im Allgemeinen eine durch Wellenenergie induzierte, auf die Küste gerichtete Migrationsrichtung (HAYEs 1980; JACKson et al. 2007), die sich im Radargramm durch landwärts einfallende Reflexionen abbildet (PEDERSEN \& ClemmenSEN 2005). Stratigraphisch kommen diese überwiegend als Vollformen ausgebildeten Sedimentkörper im Verbund mit parallel zur Küstenlinie verlaufenden linearen rinnen- oder wannenförmigen Geländedepressionen vor und gehören zu den temporären Sequenzen innerhalb des Strandprofils (FitzGerald 2005; GreEnwood 2005).

Aus dem deutschsprachigen Raum sind diese intertidalen Vollformen mit den in SCHÄFER (2005: 228 ff.) angesprochenen „Strandriffen“ vergleichbar, die als mehrfach aufeinander folgende, strandparallele Sandbänke in der Brecherzone von der senkrecht zur Küste auflaufenden Brandung aufgeworfen werden. Die Seeseite der Strandriffe ist flach.

Auf der Landseite bilden die steil einfallenden $\left(18^{\circ}-30^{\circ}\right)$ Riffstirnschichten mit landwärts orientierten Anlagerungsflächen eine parallele Schrägschichtung aus (ScHÄFER 2005).

Oft sind diese vorwiegend aus Sand aufgebauten intertidalen Sedimentkörper stratigraphisch in das Strandprofil eingebaut und aufgrund des geringen morphologischen und sedimentologischen Unterschiedes zum Strand
(JACKSON et al. 2007) nur schwer anhand von Bohrungen zu identifizieren. Die Entstehung und Anlagerung von swash bars an den Strand ist vor allem auf ruhige Phasen zwischen oder nach Sturmfluten zurückzuführen (JACKSON et al. 2007; TANNER 1995). Während den Sturmfluten werden die INTERTIDALEN Sedimentkörper zum Teil ausgeräumt, aufgearbeitet oder in ihrem oberen Bereich gekappt, sodass ein durch Wellen- und Brandungserosion bedingtes ebenes Strandprofil entsteht (FITzGERALD 2005; JACKSON et al. 2007).

Vollformen und Geländedepressionen wechseln sich innerhalb der Radarfazies Rf-AL-A2 ab und sind mit der in GReENWOOD (2005) beschriebenen typischen ridgeand-runnel-Topographie einiger Strände vergleichbar. Die konvexen Vollformen der intertidal bars oder swash bars repräsentieren dabei die Sedimentrücken (ridges). Rinneförmige Reflexionen entsprechen den sog. runnels, die von SchÄFER (2005) auch als Strandpriele bezeichnet werden. Die ridge-and-runnel-Strukturen kommen in Verbindung mit den annähernd horizontalen Reflektoren von Rf-AL-B3 vor, die als nahezu söhlig lagernde, leicht in Richtung Meer einfallende Strandsandschichten gedeutet werden. Diese zeigen die von ScHÄFER (2005: 228) als „Hochenergie-Parallelschichtung“ bezeichnete interne Sedimentstruktur. Die Ablagerung intertidaler Sedimentkörper erfolgt vorzugsweise in den Ruhephasen zwischen einzelnen Sturmfluten. Wiederkehrende Sturmfluten sorgen teilweise für die Erosion der intertidalen Vollformen und für die anschließende Ausbildung eines zeitweilig ebenen Strandprofils (JACKsON et al. 2007).

\section{$R f-A L-A 3$ Progradations-Fazies \\ Radarfazies}

Die Radarfazies Rf-AL-A3 gehört zu den einfallenden Reflexionen und setzt sich aus sigmoidal bis schräg tangential geformten Reflexionen zusammen, die in einzelne Radarschichtpakete zusammengefasst sind. Rf-AL-A3 ist ausschließlich unterhalb des Grundwasserspiegels (Rf-AL-B1) nachzuweisen. Die Reflektoren von Rf-AL-A3 verlaufen kontinuierlich bis mäßig kontinuierlich und sind von mittlerer bis starker Amplitude. Die gebündelten Reflektoren enden in der Regel mit einem downlap und zeigen ein nach Westen gerichtetes Einfallen.

\section{Sedimentfazies}

Die Radarfazies Rf-AL-A3 wurde an keiner Stelle direkt durch Bohrungen durchteuft. Die Reflektoreigenschaften und Reflexionsgeometrien sowie der Vergleich ähnlicher Reflexionsmuster (Tillmann \& Wunderlich 2011a, 2011b, 2013) lassen jedoch eine sandige Sedimentfazies vermuten.

\section{Interpretation}

Die sigmoidale Form der Reflexionen sowie die schräg tangentiale Beziehung der Reflektoren zueinander deuten auf eine progradierende Schichtung der Sedimente von Rf-ALA3 hin. Die in radar packages gebündelten Reflexionen lassen auf eine strömungsbedingte Anlagerung einzelner sandiger Sedimentpaketen schließen. Das Vorkommen von RfAL-A3 unterhalb des Grundwasserspiegels lässt zudem rein marine Sedimente vermuten. 


\section{$R f-A L-B 1$ Grundwasserspiegel}

\section{Radarfazies und Interpretation}

Rf-AL-B1 markiert einen horizontalen, durchgehenden Hauptreflektor, der der Position des Grundwasserspiegels entspricht und folglich als solcher interpretiert wird. In den gezeigten Radargrammen befindet sich der Grundwasserspiegel Rf-AL-B1 im Liegenden oder innerhalb der DünenFazies (Rf-AL-A1) und teilt die Radargramme hinsichtlich ihrer elektromagnetischen Eigenschaften in einen wassergesättigten unteren und einen wasserungesättigten oberen Teil. Bedingt durch die hohe Leitfähigkeit und den starken dielektrischen Kontrast von wassergesättigten und wasserungesättigten Sedimenten zeigt der Reflektor des Grundwasserspiegels eine starke Amplitude. Im Bereich des heutigen Kniepsandes geht der Grundwasserspiegel mit Annäherung an die MThw-Linie im Westen in salzhaltiges Brack- und Meerwasser über. Der Kontaktbereich zwischen Meer- und Grundwasser zeigt sich in den Georadardaten durch eine allgemeine Abschwächung der Reflexionen im Untergrund sowie eine nach Westen verringerte Erkundungstiefe.

\section{Rf-AL-B2 Watt-Fazies}

\section{Radarfazies}

Die Radarfazies Rf-AL-B2 umfasst horizontal planare Reflektoren, die zueinander annähernd parallel orientiert sind. Die einzelnen Reflektoren verlaufen kontinuierlich bis mäßig kontinuierlich und zeigen eine mittlere bis schwache Amplitude. Rf-SS-B2a ist ausschließlich unterhalb des Grundwasserspiegels im Tiefenbereich zwischen $-3,5 \mathrm{~m} \mathrm{NN}$ bis $-7 \mathrm{~m} \mathrm{NN}$ zu finden.

\section{Sedimentfazies}

Sedimente der Radarfazies Rf-AL-B2 wurden durch die Bohrung AL6 abgeteuft und durch diese komplett durchdrungen. Rf-AL-B2 besteht aus einer sehr feinschichtigen Wechsellagerung von Feinsand und Silt mit eingeschalteten Tonlagen. Damit umfasst die Radarfazies Rf-AL-B2 die feinkörnigsten Sedimente des Untersuchungsgebietes. Das Korngrößenspektrum der gemessenen Sedimentproben variiert zwischen feinem Mittelsand $(1,89 \varphi)$ und feinem Silt $(7,07 \varphi)$. Der Anteil an reinem Ton beträgt zwischen 4,2\%-40,7\%.

Die Sortierung der feinkörnigen Sedimente aus der Feinsand- und Silt-Fraktion ist mäßig gut $(0,59 \varphi)$ bis sehr schlecht $(3,17 \varphi)$. Eingeschaltete Mittelsand-Lagen sind mit Werten von 0,60 $\varphi-0,62 \varphi$ insgesamt besser sortiert. Die Korngrößenverteilung ist zumeist bimodal und zeigt neben dem Maximum im Feinsandbereich auch einen deutlichen Anteil an Ton. Die Sedimentfarbe ist grau bis schwarz. Innerhalb der Sedimentfazies von Rf-AL-B2 lassen sich zahlreiche gut erhaltene ca. 2-4 $\mathrm{mm}$ große Gehäuse der Wattschnecke (Hydrobia ulvae) sowie vereinzelte Mangan-Konkretionen nachweisen.

\section{Interpretation}

Im Radargramm ist Rf-AL-B2 durch horizontale Reflektoren gekennzeichnet, die auf eine ungestörte Sedimentation in horizontalen Schichten hindeuten. Im Bohrkern wird diese durch eine feinschichtige Lamination von Feinsand, Silt und Ton bestätigt.

Die dunkle Sedimentfarbe, der Gehalt an organischer Substanz und Mangan lassen auf eine Sedimentation unter reduzierenden Bedingungen schließen. Die überwiegend feinen Korngrößen von Feinsand und Silt sowie der insgesamt hohe Tongehalt zwischen 4,2\%-40,7\% sprechen für ein geringes energetisches Strömungsregime zur Zeit der Sedimentation. Gemäß der gebräuchlichen Klassifizierung nach SindowsKi $(1973,1979)$ werden die Sedimente von Rf-AL-B2 als feinsandiges Mischwatt bis Schlickwatt interpretiert. Zahlreiche Gehäuse der Wattschnecke (Hydrobia ulvae) bestätigen diesen Lebens- und Sedimentationsraum.

\section{$R f$-AL-B3 Strand-Fazies \\ Radarfazies}

Die Radarfazies Rf-AL-B3 ist im Radargramm in direktem Verbund mit Reflexionen der Radarfazies Rf-AL-A2 zu finden. Im Gegensatz Rf-AL-A2 verlaufen die einzelnen Reflektoren von Rf-AL-B3 horizontal, verhalten sich zueinander parallel bis subparallel und sind von mittlerer bis schwacher Amplitude. Wie schon die Radarfazies Rf-AL-A2 umfasst auch Rf-AL-B3 den Tiefenbereich zwischen $0 \mathrm{~m}$ und $-4 \mathrm{~m} \mathrm{NN}$ und kommt damit ausschließlich unterhalb des Grundwasserspiegels vor.

\section{Sedimentfazies}

Sedimente der Radarfazies Rf-AL-B3 umfassen schillführende Sande aus der Kornfraktion Feinsand und Mittelsand. Die durchschnittliche Korngröße bewegt sich zwischen $1,00 \varphi$ und 2,13 $\varphi$. Mit Werten zwischen 0,60 $\varphi$ und $0,97 \varphi$ sind die Sande von Rf-AL-B3 von einer mäßigen bis mäßig guten Sortierung. Die Kornverteilung ist unimodal und bimodal und zeigt nur geringe Abweichungen von der beinahe symmetrischen Schiefe. Eingeschaltete Schillhorizonte innerhalb der Strand-Fazies sind dagegen von schlechter Sortierung $(1,35 \varphi)$ und weisen eine polymodale Kornverteilung auf. In den Bohrungen ließen sich Oxidations- und Reduktionszonen innerhalb der Sedimentfazies von Rf-ALB3 belegen. Die Oxidationszonen sind durch Rostflecken sowie die eisenhaltige Umkrustung von Sandkörnern und -konkretionen gekennzeichnet.

\section{Interpretation}

Zusammen mit der Radarfazies Rf-AL-A2 umfasst die Radarfazies Rf-AL-B3 den Sedimentationsraum Strand. RfAL-A2 bildet im Radargramm die in das Strandprofil eingeschalteten intertidalen Sedimentkörper (swash bars) ab. Diese sind für die im Untersuchungsgebiet typische unruhige Strandmorphologie bestehend aus einer Kombination aus Vollformen und Geländedepressionen (ridge-and-runnel-Strukturen) verantwortlich. Dagegen besteht Rf-AL-B3 aus vorwiegend parallelen, horizontalen Reflektoren, die als annähernd söhlig lagernde, leicht in Richtung Meer einfallende Strandsandschichten gedeutet werden.

Diese lassen sich mit der von SCHÄFER (2005: 228) als „Hochenergie-Parallelschichtung“ bezeichneten, internen Sedimentstruktur vieler Strände vergleichen.

\section{Rf-AL-C1 Geschiebenester im Geestkern \\ Radarfazies und Interpretation}

Kennzeichnend für die Radarfazies von Rf-AL-C1 sind zahlreiche, sich zum Teil überlagernde Diffraktionshyperbeln, die in den Georadardaten ein chaotisches, wellenförmiges Reflexionsmuster hinterlassen. Rf-AL-C1 ist ausschließlich unterhalb des Grundwasserspiegels sowie unterhalb 
der Radarschichtfläche von Rf-AL-D1 nachzuweisen und kommt häufig in unmittelbarer Nachbarschaft zu den Reflexionen von Rf-AL-C2 vor.

Das Vorkommen von Rf-AL-C1 unterhalb der Radarschichtfläche von Rf-AL-D1 deutet auf Sedimentstrukturen innerhalb des pleistozänen Geestkerns hin. Chaotische, wellenförmige Reflexionsmuster in Kombination mit zahlreichen Diffraktionshyperbeln wurden auch in JAKOBSEN \& OvergaArd (2002) und VAN OvermeEren (1998) mit glazialen Sedimenten in Verbindung gebracht.

Auf Amrum bestehen die Sedimente der Saale-Eiszeit vorwiegend aus fluvioglazialen Schmelzwassersanden (vgl. MEIER 1987; Voigt 1969) und stark sandigem Geschiebelehm (Jessen 1932). Kalkhaltiger, toniger Geschiebemergel, wie er am Roten Kliff im Westen Sylts oder am Goting Kliff auf Föhr ansteht, ist auf Amrum nicht nachzuweisen (MüLLER \& FISCHER 1937).

Nach Krause (1913) sind die Ablagerungen der Geest auf Amrum ursprünglich durch „Ausschlämmung“ aus einer aufbereiteten Grundmoräne hervorgegangen und bestehen heute aus partiell geschichteten, geröllreichen Sanden. Der Blockreichtum Amrums im Vergleich zu den Geestkernen der Nachbarinseln spricht ebenfalls für das Hervorgehen aus einer Grundmoräne (KRAUSE 1913).

Der Geestkern der Insel Amrum zeichnet sich demnach besonders durch einen überdurchschnittlichen Geschiebereichtum aus. JESSEN (1932) weist seinerseits auf das Vorkommen sog. „Geschiebenester“ im Geestkern Amrums hin.
Diese bilden eine Konzentration von Geschieben die sich im Radargramm deutlich in Form von Diffraktionshyperbeln abbilden. Unter Rf-AL-C1 werden diese Geschiebeansammlungen innerhalb des Inselgeestkerns zusammengefasst.

\section{Rf-AL-C2 Geestkern-Fazies \\ Radarfazies}

Die Radarfazies Rf-AL-C2 zeigt schwache, diskontinuierliche Reflexionen, die insgesamt ein chaotisches Reflexionsmuster bilden. Diffraktionshyperbeln innerhalb der Radarfazies von Rf-AL-C2 sind häufig und in der Regel chaotisch innerhalb der Radarfazies verteilt. Eine untere Grenze von Rf-AL-C2 ist in den Radargrammen aufgrund verstärkter Dämpfung mit zunehmender Untergrundtiefe nicht auszumachen. Auch Rf-AL-C2 ist ausschließlich unterhalb des Grundwasserspiegels (Rf-AL-B1) und unterhalb der Radarschichtfläche (Rf-AL-D1) nachzuweisen.

\section{Sedimentfazies}

Das Amrumer Pleistozän, sofern es anhand der freiliegenden Geestoberfläche, der aufgeschlossenen Kliffabbrüche und durch die durchgeführten Bohrungen bestimmt werden konnte, besteht aus Sand- und Kiesschichten mit eingelagerten Geschieben.

Die Geestkern-Fazies Rf-AL-C2 wurde durch die Bohrungen AL1, AL2 und AL6 in unterschiedlichen Tiefen abgeteuft und setzt sich aus stark glimmerhaltigen (Muskovit) Fein- und Mittelsanden zusammen. Die durchschnittli-

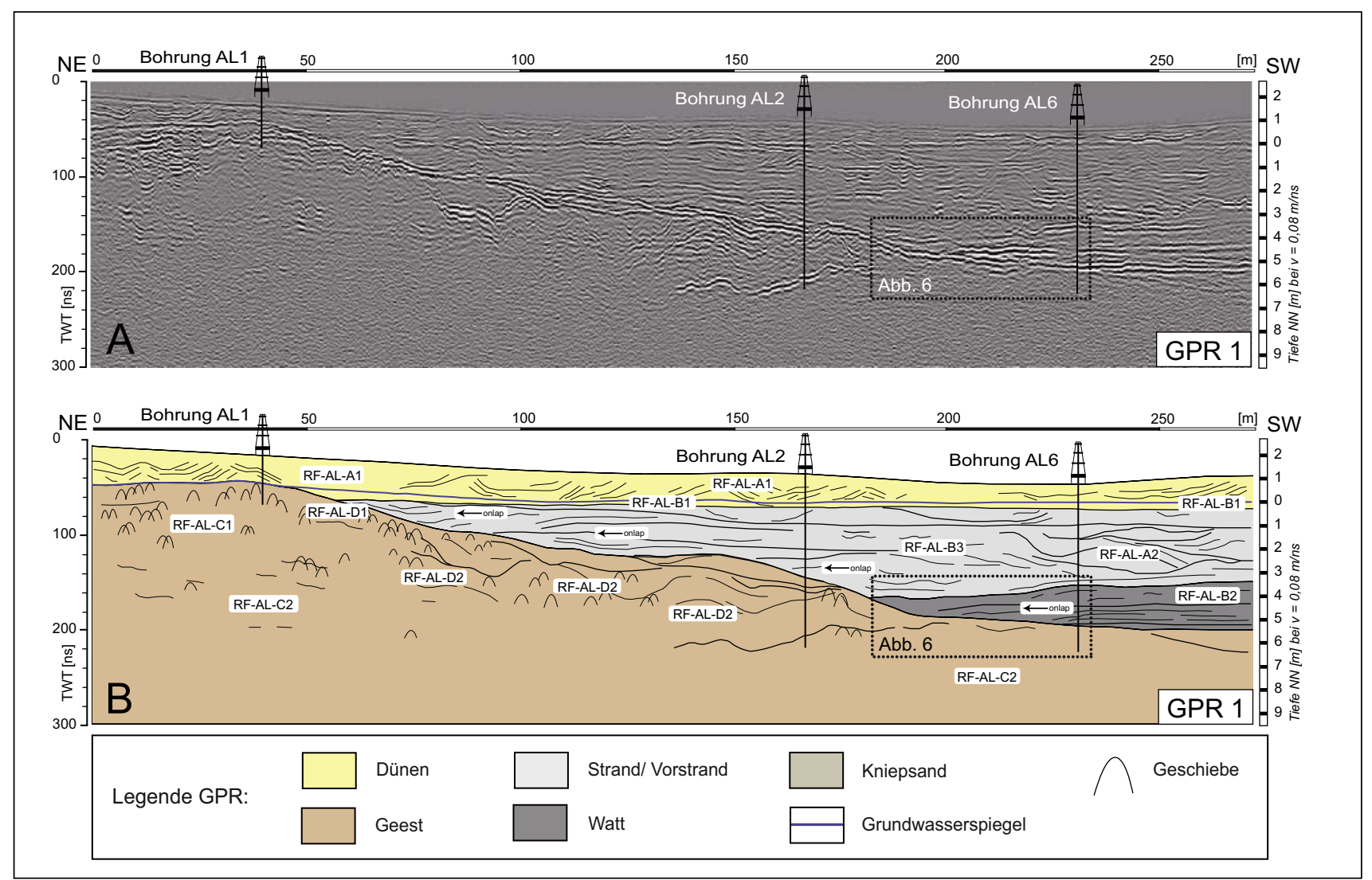

Abb. 5: GPR-Profil 1 und Position der Bohrungen AL1, AL2 und Al6. A: Für die GPR-Daten wurde ein Basis-Processing aus (static correction, subtract-mean dewow, Bandpassfilter, background removal, gain und Migration) angewandt und die Topographie mit Hilfe von dGPS Koordinaten ausgeglichen. B: Radarfazies und Interpretation von GPR-Profil 1. Die Legende gilt auch für alle weiteren GPR-Profile dieser Studie.

Fig. 5: GPR-profile 1 and position of core AL1, AL2 and Al6. A: Processing (static correction, subtract-mean dewow, bandpassfilter, background removal, gain and migration) and topographic correction of the radargramm were already applied. B: Radarfacies and interpretation of GPR-profile 1. Legend is valid for all GPR-profiles shown in this study. 
che Korngröße der Geest-Sande beträgt 1,34 $\varphi$ und 2,77 $\varphi$. Die Sortierung ist mit Werten zwischen 0,95 $\varphi$ und 0,52 $\varphi$ mäßig bis mäßig gut und ist an der Oberfläche der Geest zunehmend schlechter. Es dominieren unimodale und bimodale Korngrößenverteilungen. Vereinzelt ließen sich im Bohrkern moderat gerundete Kiese nachweisen. Muscheln oder Schillanteile konnten dagegen nicht bestätigt werden.

\section{Interpretation}

Die Radarfazies Rf-AL-C2 entspricht der internen Struktur und Schichtung im Geestkern, die sich bedingt durch geringe Materialunterschiede in Form von Reflexionen im Radargramm abzeichnet. Ursache der internen Struktur im Geestkern können sowohl primäre fluvioglaziale Sedimentationsprozesse als auch die periglaziale Umformung des oberflächennah anstehenden Geestkerns sein.

Im Gegensatz zum zentralen Sylter Geestkern bei Kampen ist der Geestkern der Insel Amrum weniger tonhaltig und setzt sich vorwiegend aus fluvioglazialen Schmelzwassersanden und stark sandigem Geschiebelehm zusammen (vgl. Jessen 1932; MEIER 1987; Müller \& Fischer 1937; Voigt 1969). Durch die geringen Tonanteile wurden innerhalb der Geestkern-Fazies von Amrum beachtliche Erkundungstiefen von bis zu 350 ns TWT bzw. 13,5 m Tiefe erreicht (Tillmann \& Wunderlich 2012).

\section{$R f$-AL-D1 Geestkernoberfläche}

\section{Radarfazies}

Die nach Westen einfallende Radarschichtfläche Rf-AL-D1 zeichnet sich durch einen kontinuierlichen Hauptreflektor mit starker Amplitude aus, der ausschließlich unterhalb des Grundwasserspiegels verläuft. An der Basis des Hauptreflektors sind zahlreiche Diffraktionshyperbeln konzentriert. Unterhalb der Radarschichtfläche kommen Reflexionen von Rf-AL-C1, Rf-AL-C2 und Rf-AL-D2 vor.

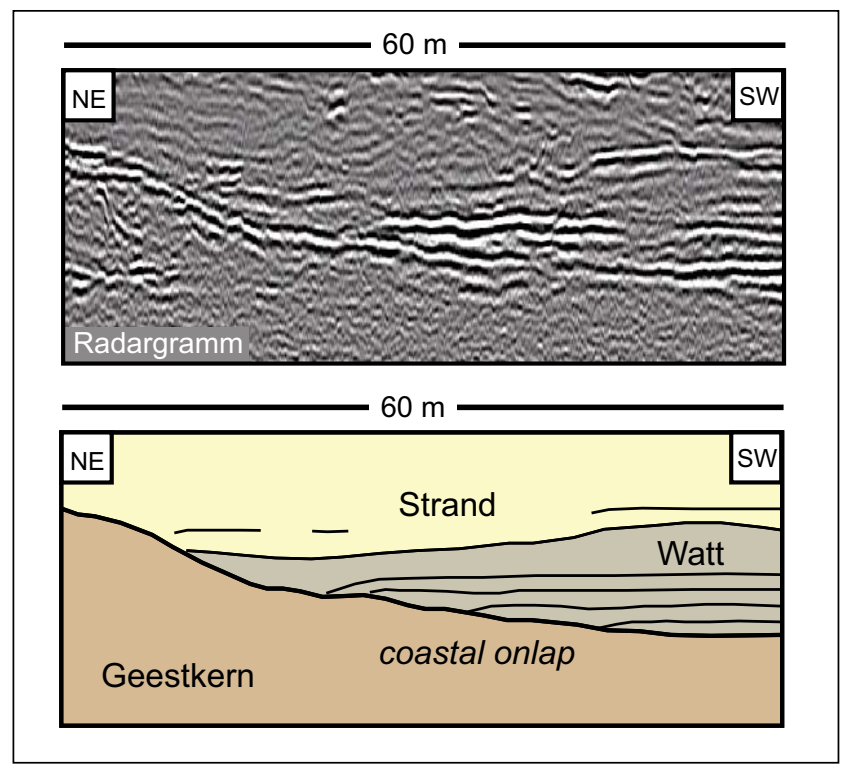

Abb. 6: Der vergrößerte Ausschnitt aus GPR-Profil 1 zeigt die coastal-onlapKonfiguration der Reflexionen im Detail. Die Position des Ausschnitts ist im Radargramm in Abbildung 5 dargestellt.

Fig. 6: The close up of GPR-profile 1 shows the coastal-onlap configuration in detail. For position of the section see figure 5 .

\section{Sedimentfazies}

Die Radarschichtfläche von Rf-AL-D1 wurde durch die Bohrungen AL1, AL2 und AL6 durchteuft und besteht im Bohrkern aus Mittelsanden mit einer durchschnittlichen Korngröße von 1,34 $\varphi-1,81 \varphi$, die in Kombination mit größeren, moderat gerundeten Kiesen vorkommen. In Bohrung AL6 ließen sich im Bereich der Radarschichtfläche Wurzeln und Vegetationsreste nachweisen, die auf einen terrestrischen Sedimentationsraum bzw. eine ehemalige Landoberfläche hindeuten. Die Sedimente dieser Geestkernoberfläche sind mit Werten zwischen 1,45 $\varphi-1,53 \varphi$ in der Regel etwas schlechter sortiert als die Sedimente, die mittels Bohrungen aus dem Inneren des Geestkerns abgeteuft wurden.

\section{Interpretation}

Die Radarschichtfläche von Rf-SS-D3 markiert die Oberfläche des nach Westen abtauchenden Inselgeestkerns und stellt zugleich die Grenze zwischen dem Holozän im Hangenden und dem Pleistozän im Liegenden dar. Die im Radargramm an der Basis der Radarschichtfläche konzentrierten Diffraktionshyperbeln entsprechen Geschieben, die sich an der Geestkernoberfläche deflationsbedingt angereichert und dort eine Steinsohle ausgebildet haben.

\section{$R f-A L-D 2$ fossile Kliffs \\ Radarfazies}

Rf-AL-D2 zeigt im Radargramm eine steil einfallende Radarschichtflächenkonfiguration mit starker Amplitude und kontinuierlichem Verlauf. Diffraktionshyperbeln lassen sich sowohl an der Basis sowie im Hangenden der Radarschichtfläche nachweisen.

\section{Sedimentfazies}

Die Radarschichtfläche Rf-AL-D2 wurde durch die Bohrung AL2 durchdrungen. Charakteristisch für Rf-AL-D2 ist eine starke Anreicherung von moderat bis gut gerundeten Kiesen. Hinsichtlich der Korngröße besteht die Radarschichtfläche aus Grobsand $(0,73 \varphi)$, der eine schlechte Sortierung $(1,26 \varphi)$ aufweist.

\section{Interpretation}

Unter Rf-AL-D2 werden Strukturen zusammengefasst, die an der Oberfläche des Geestkerns entstanden sind und sich in diesem an einigen Stellen lateral eingeschnitten haben. Die konkaven Erosionsstrukturen werden als fossile Kliffabbrüche im Bereich des Geestkerns interpretiert. Diese fossilen Kliffs entstanden infolge sturmflutbedingter Erosion am nach Westen abtauchenden Inselgeestkern. Brandungserosion führte am Geestkern zur Ausbildung von Brandungshohlkehlen und damit zur Kliffbildung.

Diffraktionshyperbeln zeugen sowohl an der Basis sowie im Hangenden der Radarschichtfläche von Rf-AL-D2 von Geschieben. Die an der Basis konzentrierten Hyperbeln entsprechen Geschiebeansammlungen am Fuße des Kliffs.

Schwerkraftbedingte Denudation von lockeren Geschieben und Kliffmaterial an den durch Sturmfluterosion versteilten Kliffhängen ist wahrscheinlich. Daher sind Geschiebe in Form von Diffraktionshyperbeln auch in der Hangrutschmasse enthalten. Hinsichtlich der Radarfazies und Sedimentfazies besteht kein bedeutender Unterschied 
zwischen dem anstehenden Geestkern und dem in der Hangrutschmasse enthaltenen Abbruchmaterial.

\subsection{Georadar-Profile}

Eine Besonderheit der GPR-Profile im Untersuchungsgebiet sind materialbedingte Geschwindigkeitsänderungen sowohl in vertikaler als auch in lateraler Richtung. Die Ausbreitungsgeschwindigkeit innerhalb trockener Dünensande beträgt $0,14 \mathrm{~m} / \mathrm{ns}-0,11 \mathrm{~m} / \mathrm{ns}$. In wassergesättigten Dünen- und Strandsanden unterhalb des Grundwasserspiegels verringert sich die Ausbreitungsgeschwindigkeit auf $0,09-0,07 \mathrm{~m} / \mathrm{ns}$. Innerhalb der saaleeiszeitlichen Geschiebeablagerungen wurden lediglich Ausbreitungsgeschwindigkeiten von $0,05-0,08 \mathrm{~m} / \mathrm{ns}$ erreicht. Auch die Wattsedimente zeichnen sich durch geringe Laufzeiten von 0,06-0,04 m/ns aus. Für die Berechnung eines einheitlichen Maßstabes wurde eine durchschnittliche Ausbreitungsgeschwindigkeit von $0,08 \mathrm{~m} / \mathrm{ns}$ zugrunde gelegt. In den GPR-Profilen wurde eine maximale Erkundungstiefe von 300-400 ns TWT erreicht. Dies entspricht im Gelände einer tatsächlichen Tiefe von 8-9 $\mathrm{m}$ unter NN.

\section{GPR-Profil 1}

Der obere Profilbereich wird ausschließlich von Reflexionen der Radarfazies Rf-AL-A1 eingenommen (Abb. 5). Innerhalb der Radarfazies Rf-AL-A1 verläuft der annähernd horizontale Hauptreflektor von Rf-AL-B1. Im südwestlichen Profilbereich von GPR-Profil 1, ab einer Entfernung von $60 \mathrm{~m}$ vom Startpunkt, finden sich im Liegenden von Rf-AL-A1 Reflexionen der Radarfazies Rf-AL-B3 und Rf-AL-A2. Während RfAL-B3 vorwiegend horizontale, nahezu parallele Reflektoren umfasst, beinhaltet Rf-AL-A2 zum Teil auch wellenförmige bis leicht geneigte Reflexionen. Die benachbarten Reflexionen von Rf-AL-B3 und Rf-AL-A2 kommen in einem Tiefenbereich von bis $\mathrm{zu}-3,5 \mathrm{~m}$ NN vor.

Die horizontalen, annähernd parallelen Reflektoren von Rf-A-B2 und Rf-A-B3 enden im Nordosten von Profil 1 mit einer deutlich ausgeprägten onlap-Konfiguration auf der Radarschichtfläche Rf-AL-D1. Besonders deutlich ist dies in Abbildung 6 ersichtlich, die einen vergrößerten Ausschnitt aus GPR-Profil 1 (Abb. 5) darstellt.

Der onlap von Rf-A-B3 vollzieht sich in einem Tiefenbereich zwischen $-0,15 \mathrm{~m}$ und $-4 \mathrm{~m}$ NN (60 ns160 ns TWT). Im Liegenden von Rf-A-B3 in einer Tiefe von $-4 \mathrm{~m}$ bis $-7 \mathrm{~m} \mathrm{NN}$ (160 ns-220 ns TWT) enden die Reflektoren von Rf-A-B2 ebenfalls durch eine onlap-Konfiguration auf der nach Westen abtauchenden Radarschichtfläche von Rf-AL-D1.

Besondere Strukturen stellen die unter Rf-AL-D2 zusammengefassten Reflexionen dar. Diese steil einfallenden Radarschichtflächen treten im Radargramm durch ihre starke Amplitude hervor und schneiden sich in die Reflexionen von Rf-AL-C2 ein. Diffraktionshyperbeln sind sowohl an der Basis als auch im Hangenden von Rf-AL-D2 konzentriert.

\section{GPR-Profil 3}

Das GPR-Profil 3 (Abb. 7) stellt das südwestliche Profilende der GPR-Profile dar und umfasst den Profilbereich zwischen $460 \mathrm{~m}$ und $810 \mathrm{~m}$ Länge, der über den Kamm der Vordüne bis auf den Kniepsand reicht (vgl. Abb. 1).
Auch in GPR-Profil 3 wird der oberste Abschnitt von Reflexionen der Radarfazies Rf-AL-A1 eingenommen. Im südwestlichen Profilbereich ist eine verstärkte Signaldämpfung und die damit einhergehende Verringerung der Erkundungstiefe zu beobachten. Im Südosten der Düne werden im Profilbereich zwischen 725 m-745 m Länge Erkundungstiefen von $-4 \mathrm{~m}$ NN erreicht. Ab dem Profilmeter 745 kommt es zu einer abrupten Signaldämpfung im Untergrund, die bis zum Ende des Profils deutlich zu verfolgen ist. Grund dafür ist das von Südwesten, aus dem Strand- und Überflutungsbereich des heutigen Kniepsandes, eindringende salzhaltige Meerwasser.

Der nordöstliche Profilbereich setzt sich in einer Tiefe zwischen 225 ns-165 ns TWT (0 m bis $-2 \mathrm{~m} \mathrm{NN}$ ) aus Reflexionen der Radarfazies Rf-AL-A2 und Rf-AL-B3 zusammen. Ab einer Tiefe von 225 ns TWT dominieren Reflexionen der Radarfazies Rf-AL-A3. Diese sigmoidal bis schräg tangentialen Reflexionen sind in einzelne, wohl definierte Radarschichtpakete gebündelt, die ein Einfallen in nordöstliche Richtung aufweisen. Zwischen 540 m-610 m Profillänge enden die Reflexionsbündel von Rf-AL-A3 in einer Tiefe von 320-350 ns TWT (ca. -5 bis -6 m NN) durch eine downlap-Konfiguration (Abb. 8).

\subsection{Sedimentologische Daten}

\section{Bohrungen AL1, AL2 und AL6}

In das Georadar-Transekt 1 wurden an drei Stellen die Bohrungen AL1, AL2 und AL6 eingebracht. AL1 befindet sich in $40 \mathrm{~m}$ Entfernung vom nordöstlich gelegenen Startpunkt des Profils und erreicht eine Bohrtiefe von $2 \mathrm{~m}$ unter der Geländeoberfläche (0 m NN). AL2 und AL6 wurden in 168 $\mathrm{m}$ und $231 \mathrm{~m}$ Entfernung vom Startpunkt eingebracht und wurden bis zu einer Tiefe von $8 \mathrm{~m}$ unter der Geländeoberfläche abgeteuft. Bohrung AL2 erreicht eine Geländetiefe von -6,25 m NN, während die maximale Geländetiefe in Bohrung AL6 -6,40 m NN entspricht. Die Ergebnisse und Korngrößenverteilung der Bohrungen AL2 und AL6 sind in den Abbildungen 9 und 10 dargestellt.

Der obere Bereich der Bohrungen AL1, AL2 und AL6 wird von holozänen Dünensanden der Fein- bis Mittelsandfraktion eingenommen. Die äolischen Fein- und Mittelsande $(2,11 \varphi-1,73 \varphi)$ sind mäßig $(0,81 \varphi)$ bis mäßig gut $(0,60 \varphi)$ sortiert und zeigen insgesamt nur geringe Abweichung innerhalb des Korngrößenspektrums. Makroskopisch erkennbare Muscheln oder Schillanteile sind nicht vorhanden. Die Kornverteilung ist unimodal bis bimodal mit dem größten Anteil an der Korngröße Mittelsand. Die Schiefe variiert zwischen -0,172 $\varphi$ und 0,148 $\varphi$.

Wurzeln des Strandhafers (Ammophila arenaria) sind in den Bohrungen AL1, AL2 und AL6 häufig und durchziehen den oberen Meter der Bohrungen AL2 und AL6. In Bohrung AL2 wurde überdies in einer Tiefe von $0,75 \mathrm{~m}$ ein ca. $20 \mathrm{~cm}$ mächtiger organisch angereicherter Boden- bzw. Wurzelhorizont nachgewiesen (Abb. 9 Bild 1), der sich bereits aufgrund des Farbunterschiedes innerhalb der hellen Dünensanden abzeichnet.

In den dargestellten Bohrungen AL2 und AL6 gehen die äolischen Dünensande im Hangenden ab einer Bohrtiefe von 1,30-1,40 $\mathrm{m}$ in die marinen Strandsande des Liegenden über (Abb. 9 und 10). Die Dünenbasis befindet sich damit 


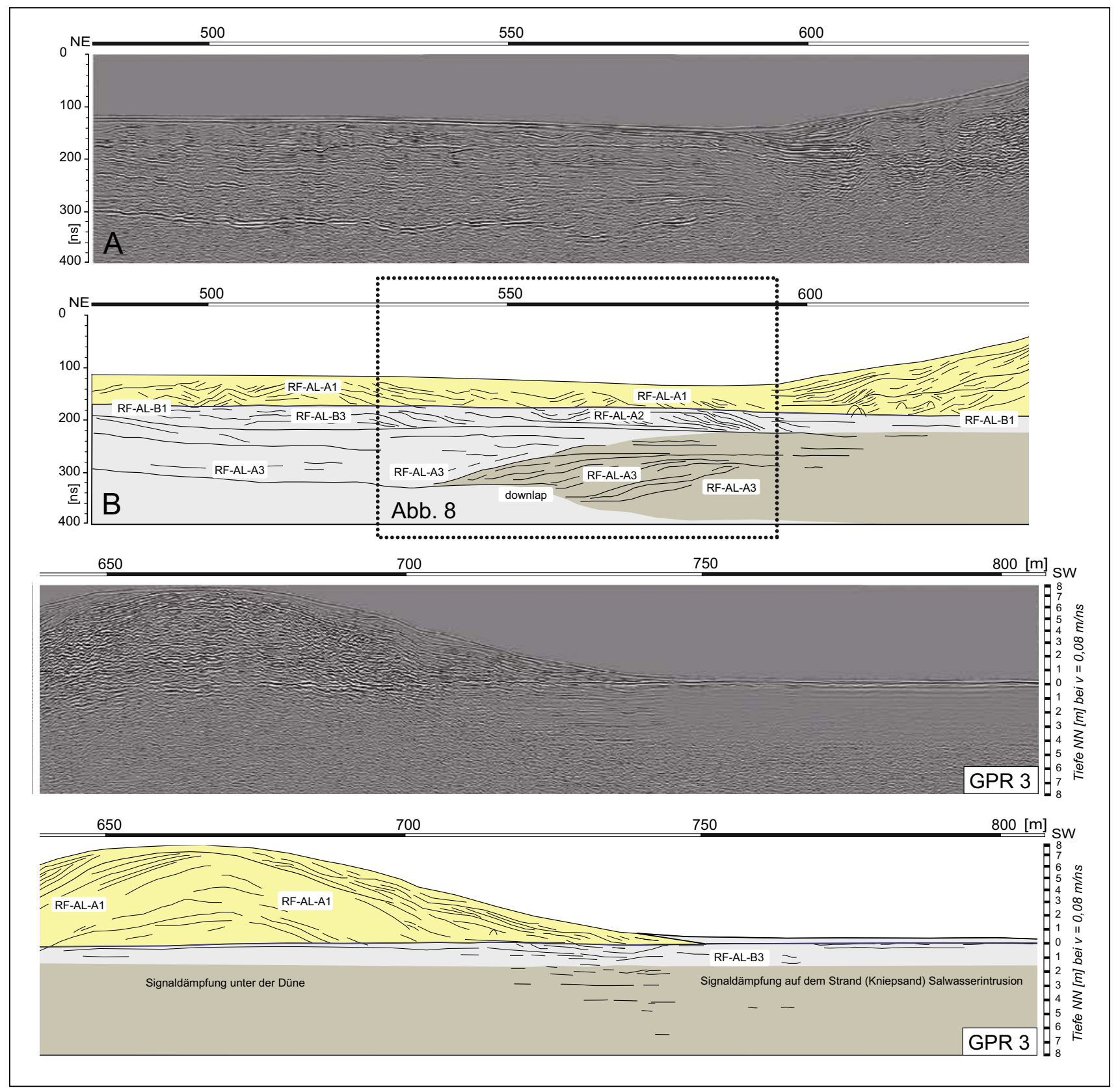

Abb. 7: GPR-Profil 3. A: Für die GPR-Daten wurde ein Basis-Processing aus (static correction, subtract-mean dewow, Bandpassfilter, background removal, gain und Migration) angewandt und die Topographie mit Hilfe von dGPS Koordinaten ausgeglichen. B: Radarfazies und Interpretation von GPR-Profil 3. Legende siehe Abbildung 5.

Fig. 7: GPR-profile 3. Processing (static correction, subtract-mean dewow, bandpassfilter, background removal, gain and migration) and topographic correction of the radargramm were already applied. B: Radarfacies and interpretation of GPR-profile 1. For legend see figure 5.

zwischen $1 \mathrm{~m} \mathrm{NN}$ und $-0,5 \mathrm{~m} \mathrm{NN}$ und liegt damit im Bereich des heutigen Grundwasserspiegels.

Die Strand-Fazies in Bohrung AL2 zeigt im Vergleich zu Bohrung AL6 insgesamt eine stärkere Variation hinsichtlich der Korngröße und Sortierung. Im Bohrkern von AL6 lässt sich anhand der Korngröße und Sortierung kaum ein Unterschied zwischen Dünen- und Strandfazies feststellen. Es dominieren Fein- und Mittelsande $(1,899 \varphi-2,003 \varphi)$. Alle Proben weisen eine mäßig gute Sortierung $(0,602 \varphi-0,612$ $\varphi)$ auf und besitzen eine symmetrische bis leicht positive Schiefe. Hinweise auf ein marines Ablagerungsmilieu geben im Bohrkern AL6 lediglich die ab einer Tiefe von $2 \mathrm{~m}$ unter der Geländeoberfläche (ca. -0,8 m NN) vermehrt vorkommenden Muschelschalen.
In einer Bohrtiefe zwischen 3 m-5 m wechseln sich Oxidations- und Reduktionshorizonte ab. Der Wechsel von Oxidation und Reduktion spricht für die zeitweilige Überflutung des Sedimentationsraums und kann daher ebenso als Indiz für ein marines Milieu gedeutet werden.

Der Strand aus Bohrung AL2 besteht aus schillführenden Fein- und Mittelsanden $(1,00 \varphi-2,13 \varphi)$, die eine mäßige bis mäßig gute $(0,60 \varphi-0,97 \varphi)$ Sortierung und eine unimodale bis bimodale Kornverteilung aufweisen (Abb. 9). Eingeschaltete Schillhorizonte innerhalb der Strand-Fazies sind von schlechter Sortierung $(1,35 \varphi)$ und weisen eine polymodale Kornverteilung auf. Wie auch in Bohrung AL6 sind die Sedimente des Strandbereichs von AL2 durch zahlreiche Oxidations- und Reduktionsspuren gekennzeichnet. Rost- 
flecken sind detailliert in Abbildung 9 (Bild 2) hervorgehoben. Überdies sind innerhalb der Strand-Fazies aus Bohrung AL2 immer wieder schwach ausgebildete Wurzelreste nachzuweisen. Im unteren Strandbereich von Bohrung AL2 lassen sich ab einer Bohrtiefe von $3 \mathrm{~m}$ zunehmend gröbere Korngrößen wie mäßig bis gut gerundete Kiese dokumentieren. Auch die Sortierung ist im unteren Strandbereich von AL2 generell schlechter als in Bohrung AL6.

Die Unterschiede der Strandsedimente von AL2 und AL6 lassen sich mit der Nähe bzw. Entfernung zu dem sich im Nordosten anschließenden Geestkliff erklären. So stellt Bohrung AL2 den kliffnahen Strandbereich dar. Dies wird vor allem durch die Anreicherung von Kiesen und Geröllen im unteren Strandbereich des Bohrkerns deutlich. Dieser Bereich entspricht morphologisch dem fossilen Klifffuß des Geestkliffs und ist so im weitesten Sinne als Teil einer Abrasionsplattform anzusehen. Die Kiese stammen ursprünglich aus dem pleistozänen Kliff und wurden durch die Brandung zu gut gerundeten Brandungsgeröllen aufgearbeitet.

Die Wurzelreste aus Bohrung AL2 deuten auf Vegetation hin, die im Vergleich zum Standort von Bohrung AL6 durch ihre Nähe zum Inselgeestkern bzw. ihrer größeren Entfernung zum Meer und der damit einhergehenden geminderten Überflutungshäufigkeit die besseren Lebensbedingungen vorgefunden hat. Es handelt sich dementsprechend um den trockenen Strand im backshore-Niveau.

Der sedimentologische Übergang zwischen Strand-Fazies im Hangenden und Watt-Fazies im Liegenden vollzieht sich im Bohrkern nur allmählich und kann durch einen Übergangsbereich beschrieben werden. Der Übergangsbereich setzt sich aus Fein- und Mittelsanden zusammen, die eine ähnliche Sortierung wie die überlagernden Strandsedimente zeigen. Eine eindeutige, allein auf sedimentologischen Kriterien basierende Unterscheidung von Strand-Fazies und Sandwatt-Fazies ist in diesem Abschnitt von Bohrung AL6 nicht möglich. Aufgrund der typischen Reflexionsgeometrien in den GPR-Daten wurde dieser Abschnitt durch die Radarstratigraphie dennoch eher zum Strandbereich gezählt.

Erst ab einer Bohrtiefe von 6,60 m (-3,75 m NN) wird ein deutlicher Wechsel hin zum feinkörnigen Misch- und Schlickwatt deutlich, das sich durch eine sehr fein laminierte Wechsellagerung von Feinsand, Silt und Ton auszeichnet. Das Korngrößenspektrum der Watt-Fazies variiert zwischen feinem Mittelsand $(1,89 \varphi)$ und feinem Silt $(7,07 \varphi)$. Der Anteil an reinem Ton beträgt zwischen 4,2\%-40,7\%.

Die in AL6 erbohrte Watt-Fazies vor der Westküste Amrums lässt sich in ein Schlick- und Mischwatt unterteilen. In Bohrtiefen von 6,60 m-7,35 m wurde ein Schlickwatt mit einem reinen Tonanteil von 13,5\%-40,7 \% nachgewiesen. Zahlreiche Gehäuse der Wattschnecke (Hydrobia ulvae) sprechen ebenfalls für ein Schlickwatt, das für die zum Makrobenthos zählende und sich als Weidegänger ernährende Schnecke einen bevorzugten Lebensraum darstellt (Отт 1996; Sommer 2005). Die Gehäuse der Schnecken sind intakt und gut erhalten. Die graue bis schwarze Sedimentfarbe und das Vorkommen von Mangan-Konkretionen geben Hinweise auf reduzierende Bedingungen (Sommer 2005) bzw. sind als Beleg für die Reduktionszone im Watt anzuführen (vgl. KösTER 1998; OTT 1996; РотT 2003; SINDOWSKI 1973).

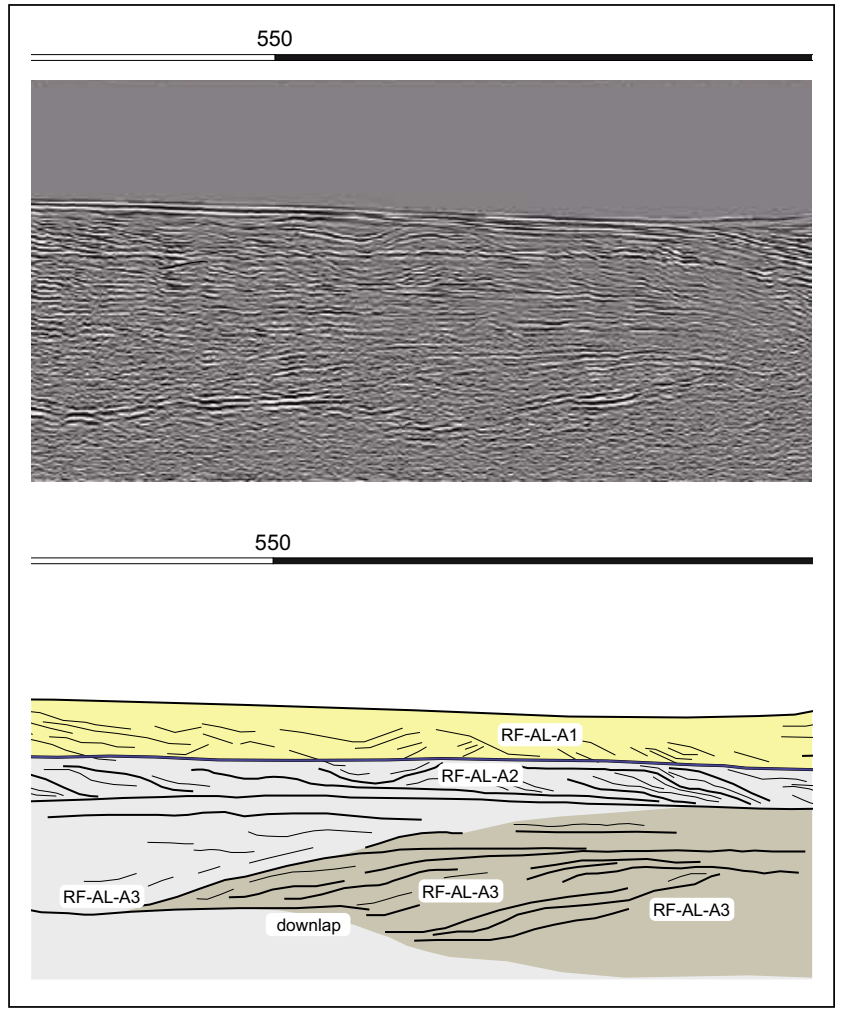

Abb. 8: Vergrößerter Ausschnitt aus GPR-Profil 3. Zur Position des Ausschnitts innerhalb des Profils siehe Abbildung 7. Der Ausschnitt zeigt die ostwärts gerichtete Wanderung des Kniepsandes.

Fig. 8: The close up of GPR-profile 3. For position of the close up see figure 7. The section shows the eastward migration of the Kniepsand.

In Bohrung AL6 wird das Schlickwatt zum Hangenden hin zunehmend grobkörniger und geht ab einer Bohrtiefe von 6,60 $\mathrm{m}$ in ein feinsandiges Mischwatt mit einem Tonanteil von unter 5,6\% und einer durchschnittlichen Korngröße von 2,45 $\varphi-1,89 \varphi$ über. Die Sedimentfarbe wird zum Hangenden hin insgesamt heller (Abb. 10) und deutet auf weniger stark reduzierende Bedingungen bzw. eine bessere Durchlüftung der Sedimente mit Sauerstoff hin.

Die feinen Korngrößen von Feinsand und Silt sowie der insgesamt hohe Tongehalt sprechen für ein geringes energetisches Strömungsregime zur Zeit der Sedimentation. Infolgedessen wird angenommen, dass die Wattsedimente aus Bohrung AL6 aus einer Stillwassersedimentation an einer „Niederenergieküste“ (SCHÄFER 2005: 243) hervorgegangen sind. Solche ruhigen Sedimentationsbedingungen sind heute hauptsächlich im Bereich der Rückseitenwatten und im strömungsberuhigten Lee einer Insel oder Küstenbarriere zu finden.

Heute herrschen an der Westküste Amrums jedoch hochenergetische Strömungsbedingungen. Die erbohrten Wattsedimente müssen demzufolge unter abweichenden, ruhigeren Sedimentationsbedingungen dort zur Ablagerung gelangt sein. Es ist davon auszugehen, dass dies im Lee einer der Westküste vorgelagerten Barriere oder Sandbank geschah. Es wird daher angenommen, dass der damals noch weit vor der Küste Amrums liegende Kniepsand diese Barriere bildete und so an der Westküste für strömungsberuhigte Sedimentationsbedingungen sorgte.

Die Geest-Fazies wurde durch die Bohrungen AL1, AL2 und AL6 direkt erreicht (Abb. 9 und 10). Dabei fällt die Ober- 


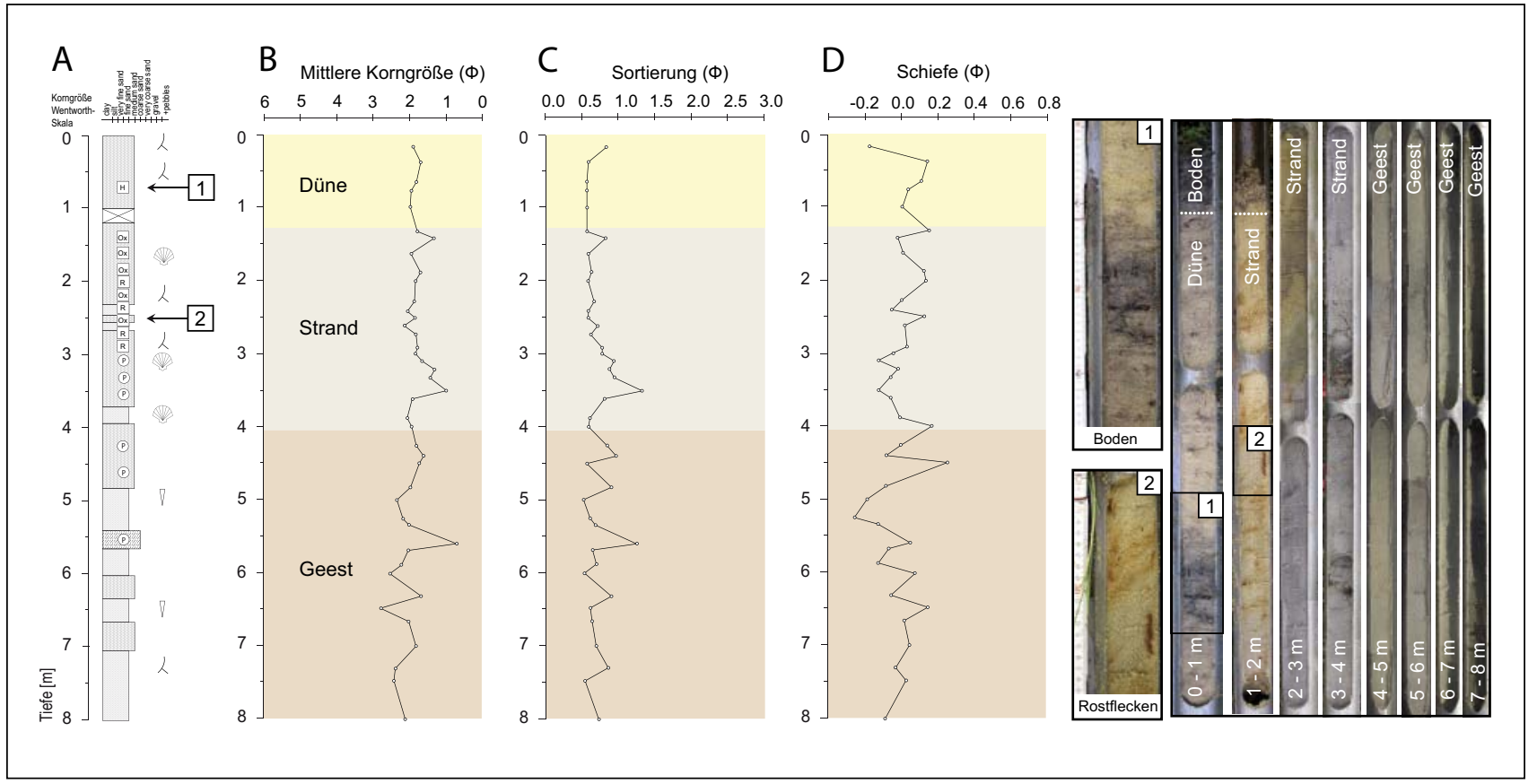

Abb. 9: Bohrkern (A) und Korngrößenstatistik $(B-D)$ von Bohrung AL2. Legende siehe auch Abbildung 10. Bild 1 markiert einen Paläoboden innerhalb der Dünenfazies. Bild 2 zeigt eine Oxidation der Strandsedimente.

Fig. 9: Core log $(A)$ and grain size statistic $(B-D)$ of core AL2. Legend is provided in figure 10. Picture 1 shows a palaeosoil within the dune facies. Picture 2 shows oxidation of beach deposits.

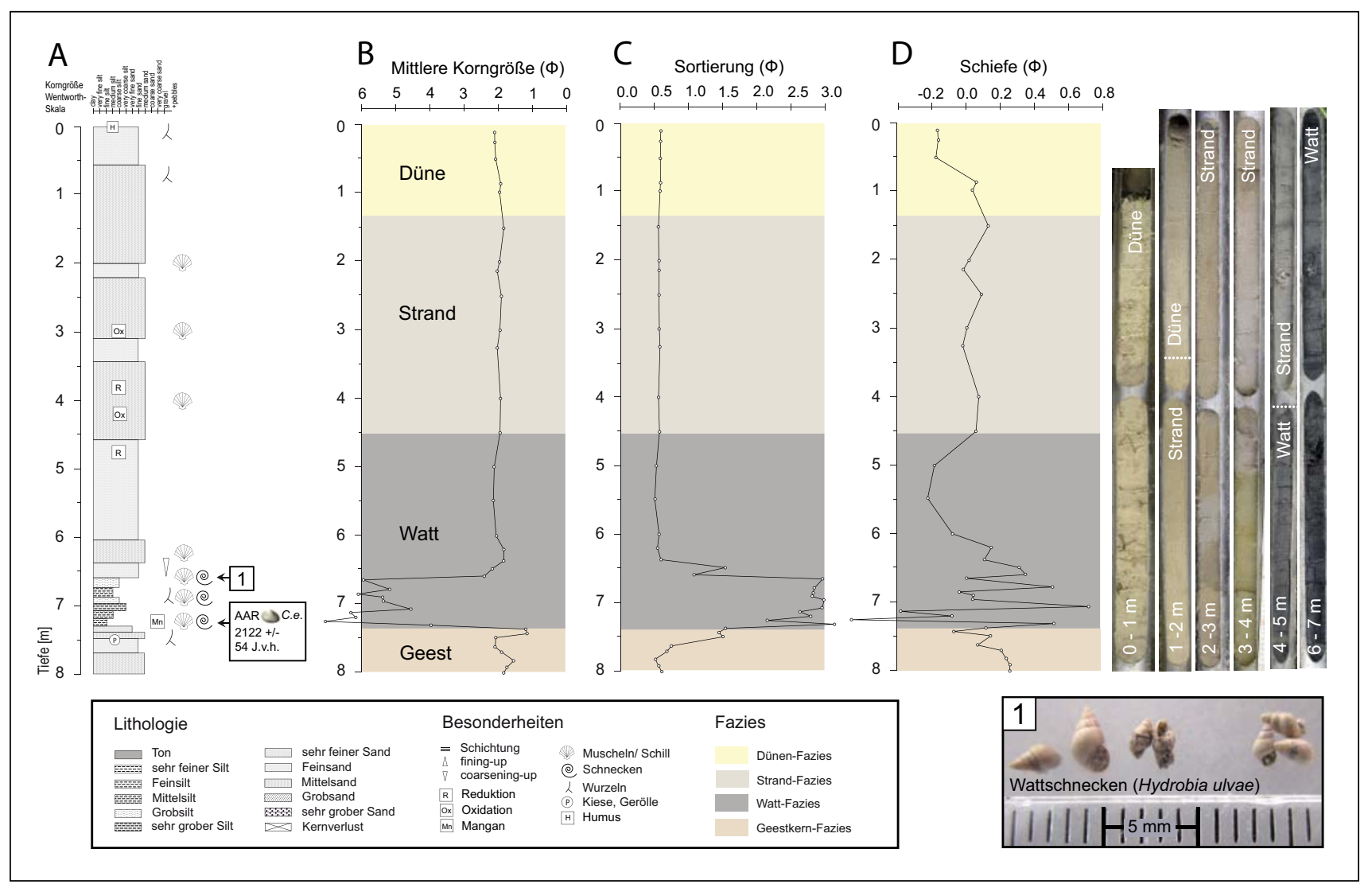

Abb. 10: Bohrkern (A), Korngrößenstatistik (B-D) und Legende von Bohrung AL6. Bild 1: Hydrobia ulvae.

Fig. 10: Core log $(A)$, grain size statistic $(B-D)$ and legend of core AL6. Picture 1: Hydrobia ulvae. 
fläche der Geest in den Bohrungen AL1, AL2 und AL6 von Nordosten nach Südwesten ab. Während die Geest in Bohrung AL1 direkt unterhalb der Dünenfazies ansteht und in einer Bohrtiefe von 1,20 m (0,8 m NN) erreicht wurde, fällt die Oberfläche in den Bohrungen AL2 und AL6 auf $4 \mathrm{~m}$ und 7,45 m Tiefe ab. Damit steht die Geest in Bohrung AL2 bei $-3,15 \mathrm{~m} \mathrm{NN}$ und in Bohrung AL6 bei -5,25 m NN an.

Die Geestkern-Fazies setzt sich in den Bohrungen AL1, AL2 und AL6 aus stark glimmerhaltigen Fein- und Mittelsanden zusammen. Es dominiert der helle Glimmer (Muskovit). Die durchschnittliche Korngröße der Geest-Sande beträgt $1,34 \varphi$ und 2,77 $\varphi$. Die Sortierung ist mit Werten zwischen $0,95 \varphi$ und $0,52 \varphi$ mäßig bis mäßig gut und ist an der Oberfläche der Geest meist etwas schlechter. Der Übergang von der Geest-Fazies im Liegenden zur WattFazies im Hangenden wird durch eine Anreicherung von groben Kornkomponenten und Kiesen begleitet, die sedimentologisch auf eine gut ausgebildete Steinsohle hinweisen.

Überdies konnten in Bohrung AL6 in einer Tiefe von 7,45 m (-5,25 m NN) Wurzeln nachgewiesen werden. Wurzeln an dieser stratigraphischen Position sprechen für den Bewuchs der Geestoberfläche und damit für ehemals terrestrische Bedingungen an dieser einstigen Landoberfläche. Die Annahme eines terrestrischen Ablagerungsraumes wird durch das Fehlen von Muscheln und Schill unterstützt.

\section{Diskussion \\ 5.1 Coastal onlap Modell}

Auf der Grundlage der gemessenen GPR-Profile und durchgeführten sedimentologischen Analysen aus den Bohrungen AL1, AL2 und AL6 wurde ein stratigraphisches Modell entwickelt. Das Modell beschreibt die Landschaftsentwicklung an der Westküste Amrums in einer Zeit, bevor sich der von Westen heranwandernde Kniepsand an die Insel angelagert hat.

Die geologische Ausgangssituation ist ein leicht nach Westen abfallender Geestkern bestehend aus Endmoränenrelikten der Saale-Eiszeit. Von Westen aus folgt die Anlagerung rein mariner Sedimente, die als „coastal onlap“ (CATUNEANU 2002; EMERY \& MYERs 1996) beschrieben werden kann. Coastal onlap Konfigurationen sind vor allem aus seismischen Daten vom Kontinentalhang bekannt (vgl. EMERY \& MYERs 1996). In Georadardaten konnte ein coastal onlap-Prozess hingegen bislang noch nicht nachgewiesen bzw. unmittelbar durch Radargramme abgebildet werden.

Sedimentologisch besteht der Geestkern im Untersuchungsgebiet aus muskovithaltigen Fein- und Mittelsanden mit vereinzelt eingeschalteten Geschieben, die auf fluvioglaziale Schmelzwassersande zurückzuführen sind (vgl. auch Jessen 1932; Krause 1913; MeIer 1987; Voigt 1969).

Der Übergang zwischen Geestkern im Liegenden und Watt im Hangenden wird durch eine Steinsohle gebildet, die der ehemaligen Landoberfläche entspricht und zugleich die Grenze zwischen Pleistozän und Holozän darstellt. Wurzeln zeugen von terrestrischen Bedingungen und dem einstigen Bewuchs dieser Landoberfläche, die durch einsetzende Transgression allmählich von Westen her überflutet wurde.
Mit der Transgression folgten Ablagerungen eines Watts. Die Wattsedimentation im Vorfeld des nach Westen abtauchenden Geestkerns stellt damit die zeitlich erste aus den o. g. Daten ersichtliche Phase dar (Abb. 11 Bild 1). Die Ablagerungen dieses Westküstenwatts konnten in den Daten bis zu einer Tiefe von -7 m NN verfolgt werden. Im Liegenden wurden zunächst horizontal geschichtete Wattsedimente eines Misch- bis Schlickwatts abgelagert, die zum Hangenden hin grobkörniger werden und in ein Sandwatt übergehen. Der Sedimentationsraum wird durch Funde von Wattschneckengehäuse in der Bohrung AL6 bestätigt.

Eine grobe zeitliche Einordnung des Westküstenwatts aus Bohrung AL6 erfolgte lediglich mittels AAR-Datierung an einer intakten Muschelschale der Herzmuschel (Cerastoderma edule), die aus einer Bohrtiefe von $728 \mathrm{~cm}$ gewonnen wurde. Auf diese Weise konnte für die Wattsedimente in einer Tiefe von -5 m NN ein Mindestalter von $2122+/-54$ Jahren definiert werden. Die datierten Wattsedimente zählen zu den ersten, die auf dem „ertrinkenden“ Geestkern abgelagert wurden und entsprechen damit der Position des Transgressionskontaktes. Es ist demzufolge davon auszugehen, dass die Überflutung dieses Bereiches der Westküste Amrums bereits vor $2122+/-54$ Jahren einsetzte.

Bereits FALK (2001) geht vor der Westküste Amrums von wattähnlichen Bedingungen aus. Im Vorfeld der Bohrungen AL2 und AL6 wurden nach FALK (2001) im Subboreal ausschließlich marine klastische Sedimente abgelagert, die allerdings bisher nicht näher hinsichtlich ihrer Genese identifiziert, unterteilt sowie räumlich und zeitlich abgegrenzt wurden.

So wurde nach Übereinstimmung mit FALK (2001) das Gebiet der Westküste Amrums zunehmend an der Grenze zwischen Subboreal und einsetzendem Subatlantikum von der Transgression erreicht, sodass mit steigender Überflutung Wattsedimente dort abgelagert wurden. Da eine Torfbildung an der Basis der holozänen Wattsedimente fehlt wird von einem raschen Vordringen der See ausgegangen. Die transgredierende Nordsee erreicht im Subboreal zuerst über das Tief der Norderaue das Untersuchungsgebiet von Südosten her (FALK 2001). Die Bohrungen AL2 und AL6 lagen im Subboreal noch außerhalb des Überflutungsbereichs.

Aus Chroniken ist zu entnehmen, dass es noch Anfang des 19. Jahrhunderts „grüne Marschwiesen“ weit westlich von Amrum gegeben haben soll, auf denen "Schafe“ weiden konnten (MeYN 1876; MÜlLER \& FISCHER 1937; JeSSEN 1914). Eine genaue Lagebestimmung und Position dieser „Marschwiesen“ vor der Küste Amrums wurden jedoch nie überliefert. Festgehalten werden kann dennoch, dass im Vergleich zu heute ruhigere Sedimentationsbedingungen im Vorfeld der Westküste Amrums geherrscht haben müssen.

Aus historischen Land- und Seekarten (vgl. Abb. 2) ist hingegen ersichtlich, dass sich der Kniepsand auf der Höhe des Leuchtturms bereits vor 1841 an die Insel angelagert haben muss, sodass zu und nach dieser Zeit und an dieser Stelle vor der Westküste Amrums keine „Schafe“ auf „Marschwiesen“ weiden konnten.

Glaubt man der Landkarte von JoHANnES MEJER aus dem Jahr 1648 (DANCKWERTH 1652), so lag der Kniepsand 1648 als solitäre Sandbank oder Untiefe noch weit vor der 


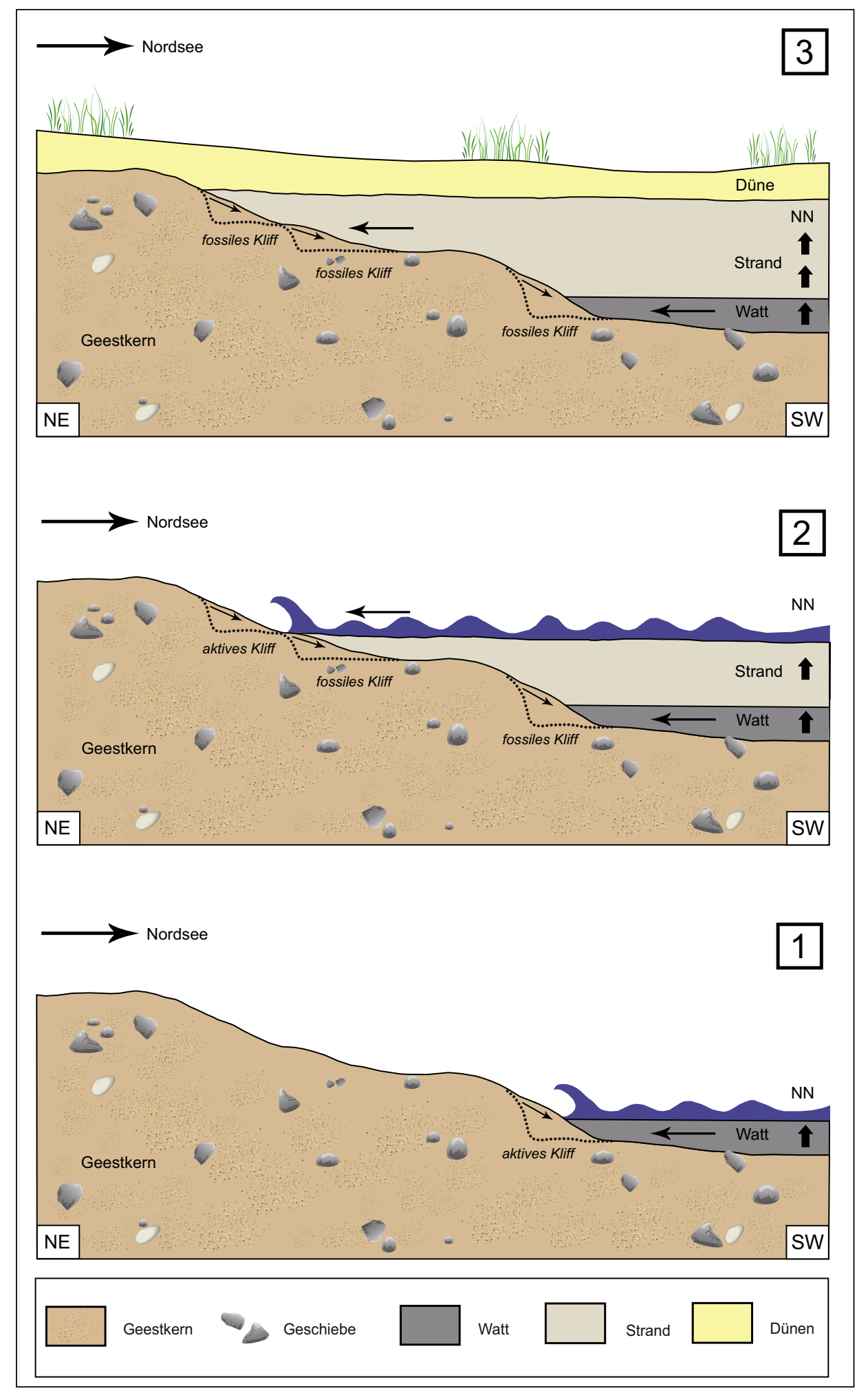

Abb. 11: Das Coastal-onlap Modell zeigt die Landschaftsentwicklung vor der Westküste der Insel Amrum. Bild 1: Im Küstenvorfeld der Insel Amrum wurden zunächst feinkörnige Wattsedimente abgelagert. Bild 2: Durch einen Anstieg des Meeresspiegels und die ostwärts gerichtete Migration des Kniepsandes folgten gröbere Strandsedimente. Sturmfluten führten gleichzeitig zur Erosion am Geestkern und schufen aktive Kliffs, die mit ansteigendem Meeresund Sturmflutspiegel in fossile Kliffs übergingen. Bild 3: Durch die endgültige Anlagerung des Kniepsandes an die Insel wurde der nötige Sedimentinput für großflächige Dünenbildung geliefert.

Fig. 11: The coastal-onlap Model shows the landscape development in front of the westcoast of Amrum. Picture 1: Before the barrier sandbar was connected to the island, tidal flat deposits had been accumulated in a low energy environment. Picture 2: Tidal flat deposits show a general coarsening upward trend and turn into overlying coarser grained beach deposits under a rising sea level. Old cliffs formed through several storm surges are also preserved in GPR data. Picture 3: Fine to medium grained beach sand was reworked and blown out to build up some primary foredune ridges which enhance to shape the present dune area.

Westküste Amrums. Demnach können in der Zeit von 1648 bis zur Anlagerung des Kniepsandes an die Insel durchaus strömungsberuhigte Sedimentationsbedingungen geherrscht haben, die im Westküstenvorfeld zu Ausbildung von Watt- und Marschflächen führten. Denkbar ist, dass der solitäre Kniepsand seinerseits eine Barriere darstellte und so im Lee die ruhigen Sedimentationsbedingungen an der Westküste Amrums zum Teil förderte.

Eine Anlagerung des Kniepsandes an die Insel wird daher für die Zeitspanne zwischen 1648 und 1841 angenommen.

Im weiteren Verlauf der Transgression wurden die Ab- lagerungen zunehmend gröber. Im Hangenden des Westküstenwatts folgten Strandablagerungen (Abb. 11 Bild 2), die im Vergleich zum Watt eine unruhige Strandmorphologie zeigen. Die Morphologie wird durch vereinzelte in das Strandprofil eingeschaltete intertidale Sedimentkörper (intertidal bars, swash bars) und parallel zur Küste verlaufende Rinnen bedingt, die eine ridge-and-runnel-Topographie des Strandes hervorrufen.

Die verhältnismäßig große Breite sowie die flache nur leicht in Richtung Meer einfallende Topographie des Strandes und die Anlagerung von intertidalen Sedimentkörpern 
lassen auf einen dissipativen Strand schließen. Sturmfluten führten neben Klifferosion am Geestkern ebenso zur Erosion und morphologischen Umgestaltung im Strandbereich. Dabei wurden die intertidalen Sedimentkörper zum Teil ausgeräumt, aufgearbeitet oder in ihrem oberen Bereich gekappt (FitzGerald 2005; JACKSON et al. 2007), sodass zeitweilig ein ebenes Strandprofil aus horizontalen Strandsandschichten mit ausgeprägter Hochenergie-Parallelschichtung (SCHÄFER 2005) entstand.

Die fossilen Geestkernkliffs zeigen im Radargramm (Abb. 5) deutliche, durch wiederholte Abrasion infolge von Sturmfluten geschaffene Brandungshohlkehlen im unteren Kliffbereich. Gravitative Hangabtragung des oberen Kliffbereichs bzw. ein denudatives Nachrutschen von Kliffmaterial aus dem Hangenden ist anhand von Schutthalden am Klifffuß erkennbar. Diese Kliffhalden sind in den GPRDaten durch eine Anreicherung von Diffraktionshyperbeln ersichtlich. Auch sedimentologisch lassen sich dem Bereich insgesamt gröbere Korngrößen sowie vereinzelt Brandungsgerölle nachweisen. Damit entspricht dieser dem Kliff vorgelagerte Strandbereich geomorphologisch einer Abrasions- oder Strandplattform.

Bereits MÜLLER \& FISCHER (1937: 10) entdeckten westlich des Leuchtturms ein „[...] Steinplaster aus groben, teils faustgroßen Geröllen [...]“, das sie als „[...] Brandungsterrasse, die aus den bei der Unterspülung nachgestürzten Geschieben [...]" im damaligen Kliffbereich gebildet wurde deuteten.

Die Abfolge aus Geestkern, Kliff, Brandungshohlkehle, Kliffhalde und Abrasionsplattform mit Brandungsgeröllen kann als „littorale Serie“ zusammengefasst werden, die allerdings weniger stark ausgeprägt ist. Begründet ist dies auf der Tatsache, dass sich der Geestkern von Amrum an dieser Stelle nur durch gering verfestigte pleistozäne Sande mit Geschiebeeinlagerungen darstellt, der nur bedingt ein Kliff von geringer Höhe ausbildet. Dementsprechend unscheinbar ist auch die dem Kliff vorgelagerte Abrasionsplattform, die sich ebenso aus Lockersedimenten zusammensetzt.

Fossile Kliffs in unterschiedlichen Höhenpositionen im Bereich des Geestkerns lassen auf unterschiedliche Meeresspiegelniveaus schließen. Ein Anstieg des Meeres- und Sturmflutspiegels führte zur Erosion und Kliffbildung am Geestkern. So entspricht die Höhe des jeweiligen Klifffußes dem Sturmflutspiegelniveau der entsprechenden Bildungszeit (Abb. 5 und 11). Das obere fossile Kliff kann als Vorstufe des Littorina Kliffs gesehen werden. REmdE (1972) geht davon aus, dass sich das Nord- und Südende des Littorina Kliffs noch vor etwa 150 Jahren im Abbruch befand und sich erst danach zum fossilen Kliff entwickelte.

Die jüngste stratigraphische Einheit im Untersuchungsgebiet stellen die heutigen Dünen dar, die sich nach Ende der Transgression und mit Anlagerung des Kniepsandes an die Westküste der Insel großflächig bildeten und damit die Geest allmählich bedeckten (Abb. 11 Bild 3).

\subsection{Andockmodell des Kniepsandes an die Insel Amrum}

Auf der Grundlage von GPR-Profil 3 konnte ein zweites Modell entwickelt werden, das die Migration und letztendlich das „Andocken“ des Kniepsandes an den zentralen Insel- geestkern an der Westküste Amrums beschreibt (Abb. 12).

Generell zeigt der ehemalige Weststrand der Insel Amrum noch vor Anlagerung des heutigen Kniepsandes eine leicht nach Südwesten einfallende Schichtung im Unterwasserbereich (Abb. 12 Bild 1). Auf westlicher Seite erfolgten das Heranwandern und die Annäherung des ehemals als solitäre Sandbank vor der Westküste lagernden Kniepsandes (Abb. 12 Bild 2). Die nach Nordosten gerichtete Wanderungstendenz des Kniepsandes zeigt sich in GPRProfil 3 besonders deutlich zwischen den Profilmetern 540610 (Abb. 7 und 8). Die sigmoidale Form der Reflexionen sowie die tangentiale Beziehung der Reflektoren deuten dort auf eine progradierende Schichtung der Sedimente hin. Die in Radarschichtpakete gebündelten Reflexionen lassen auf eine strömungsbedingte Anlagerung einzelner sandiger Sedimentpakete schließen. Die Anlagerung von Sedimenten an die „Stirn“ des Kniepsandes erforderte einen strömungsbedingten Sedimenttransport in östliche Richtung.

Zeitlich erfolgte die Bildung des ursprünglichen Strandes an der Westküste von Amrum vor der Anlagerung des Kniepsandes an die Insel. Stratigraphisch ist der Kniepsandkörper in die ursprünglichen Sedimente des Strandes vor der Westküste Amrums eingearbeitet (Abb. 12 Bild 2).

Die deutlich erkennbare downlap-Konfiguration aus den GPR-Daten zeigt, dass sich der Kniepsandkörper an seiner „Stirn“ auf die Strand- und Vorstrandsedimente heraufgeschoben hat. Der Bereich zwischen den Profilmetern 540 610 wird infolgedessen als „Andockzone“ interpretiert und stellt damit geologisch die Grenzen zwischen der Insel und dem Kniepsand dar. Die Zone zwischen dem ursprünglichen Strand und dem heranwandernden Kniepsand zeigt im Radargramm nur wenige Reflexionen. Gründe dafür können ein homogener Sedimentkörper bzw. eine nur undeutlich bis wenig ausgeprägte Schichtung innerhalb der Mischzone der Andockstelle sein. Die Vermischung der beiden Sedimentkörper wurde in der Folgezeit durch strömungsbedingte marine Vorgänge im Unterwasserbereich sowie durch äolische Vorgänge im trockenen Bereich des Strandes gefördert (Abb. 12 Bild 3).

Nach Ende der Transgression bzw. mit dem Trockenfallen der entstandenen Sandflächen wurden die Bedingungen für die anschließende großflächige Dünenbildung geschaffen. Höchstwahrscheinlich führte die Anlagerung des Kniepsandes im Westen zum Sedimentinput und stellte den Sand zur vermehrten Dünenbildung zur Verfügung (Abb. 12 Bild 4).

Die Dünen generierten sich aus dem Kniepsand, wanderten über den Strand hinweg, begruben das Geestkliff und schoben sich den flachen Geestkern hinauf. Auf diese Weise wurde das Geestkliff vor der Brandung und vor fortschreitender Abrasion geschützt und entwickelte sich allmählich zum toten Kliff.

Morphologisch ist das Geestkliff im Untersuchungsgebiet als verdeckter Teil des weiter nördlich bei „A Hörn“ oberflächennah aufgeschlossenen Littorina Kliffs $\mathrm{zu}$ sehen und steht mit diesem in unmittelbarer Verbindung. Bei „A Hörn“ („die Ecke“) erreicht das Littorina Kliff mit 13 m NN heute seine größte Höhe und taucht in Richtung Leuchtturm relativ kontinuierlich ab (REMDE 1972).

Auch die Dünen auf dem Geestkern Amrums wurden daher vermutlich erst nach Anlagerung des Kniepsandes 


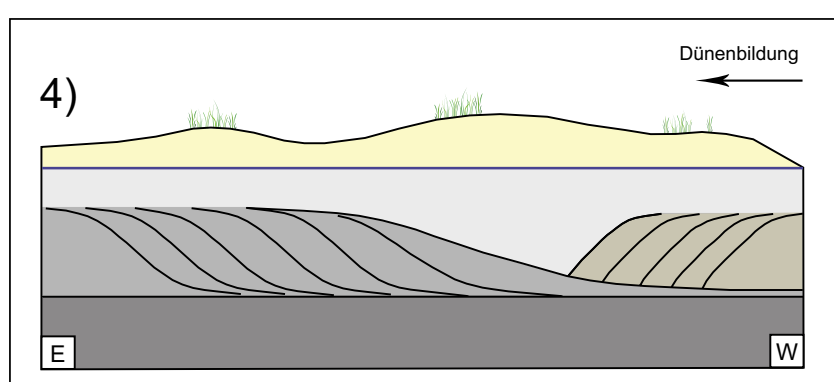

3)
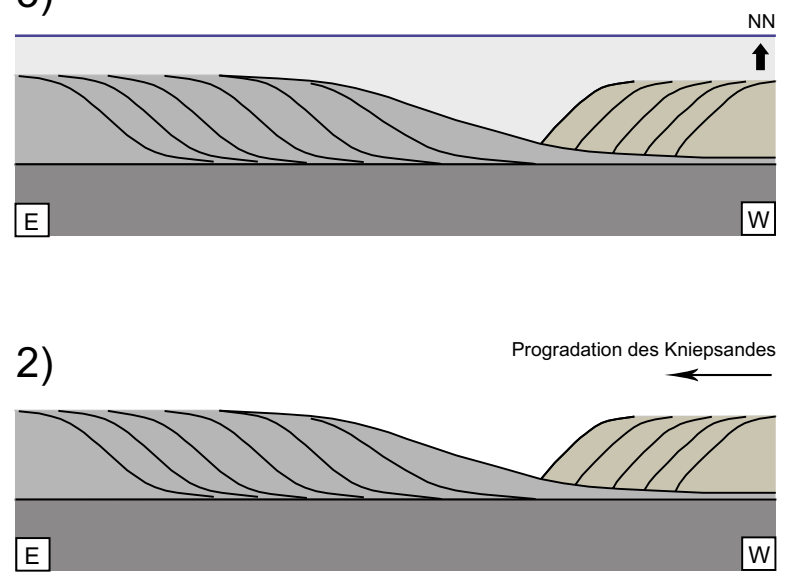

1)
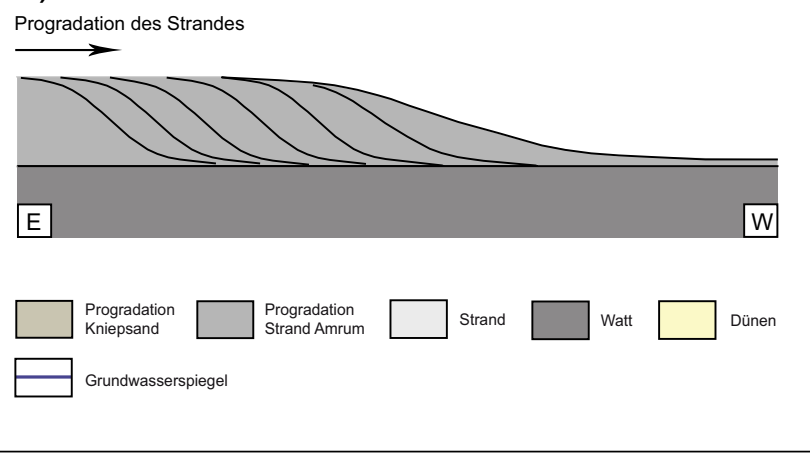

Abb. 12: Andockmodell des Kniepsandes an die Insel Amrum. Bild 1 zeigt den ursprünglichen Strand an der Westküste der Insel Amrum. Bilder 2-3 zeigen das Heranwandern des Kniepsandes an die Insel unter steigendem Meeresspiegel. Bild 4: Anschließend setzte durch vermehrten Sedimentinput großflächig Dünenbildung ein.

Fig. 12: Picture 1 shows the early beach in front of the west coast of Amrum. Pictures 2-3 show how the Kniepsand migrates to the island under a rising sea level. Picture 4: The input of sediment leads to dune building.

an die Insel gebildet. Zeitliche Anhaltspunkte für die Dünenbildung liefern die „mittelalterlichen Ackerbeete“ die als Kulturspuren unter den Dünen der Geest hervortreten (GrIPP 1968). Unweit des Amrumer Leuchtturms wurden zudem Pflugfurchen, Viehspuren und Ackerbeete entdeckt, deren Kultivierung gemäß der darin enthaltenen Scherben auf das 14. Jahrhundert zurückgeht (KeRSTEN 1969; REMDE 1972). Weiter zeitlich eingrenzen lässt sich die Anlagerung des Kniepsandes an die Insel Amrum unter Beachtung historischer Land- und Seekarten. So wird ein Andocken des Kniepsandes an die Insel auf der Höhe des Untersuchungsgebietes für die Zeitspanne zwischen 1648 und 1841 angenommen.
In seiner „Chronik der friesischen Uthlande“ vermerkte C. P. HANSEN (zitiert nach MüLler \& FISCHER 1937: 65) für das 16. Jahrhundert jedoch: „[...] Amrum war damals wie jetzt ein mehrenteils dürres Land von Heide und Dünen, klein an Fläche, aber mit großen, weit hinausreichenden, für die Seefahrer gefahrvollen Sandbänken umgeben [...] und schilderte auf diese Weise morphologisch die Situation sowohl des noch unweit vor der Küste liegenden Kniepsandes als auch der einsetzenden Dünenbildung. Auch HANSSEN (1835: 484) teilte in einem Bericht über die Pastoratsländereien von 1629 mit: „[...] schon damals war Wiesenland durch Dünen verloren gegangen [...] “ und beschrieb damit die Auswirkungen der Dünenbildung.

Der Kniepsand stellt heute aus geomorphologischer Sicht den Strand an der Westküste der Insel Amrum dar. Dieser erstreckt sich heute südwestlich des ersten Dünengürtels. Die ursprüngliche aus den Georadar-Daten ersichtliche „Andockstelle“ des Kniepsandes an die Insel befindet sich jedoch $50 \mathrm{~m}$ nordöstlich der Vordüne und liegt damit heute bereits im rückwärtigen Dünengelände. Damit befindet sich die Andockstelle bzw. die Nahtstelle zwischen Kniepsand und eigentlicher Insel etwa 200 m weiter nordöstlich als dies heute der Fall ist.

\section{Zusammenfassung und Schlussfolgerung}

Georadarmessungen, Bohrungen und sedimentologischen Analysen haben sich als geeignete Methodenkombination zur Rekonstruktion der Landschaftsentwicklung an der Westküste der Insel Amrum erwiesen. Auf Grundlage der gewonnenen Daten wurden zwei stratigraphische Modelle entwickelt, welche die geologisch-geomorphologischen Prozesse und Sedimentationsbedingungen im Westküstenvorfeld erklären.

Das erste Modell zeigt die Landschaftsentwicklung an der Westküste Amrums und beschreibt die Sedimentationsbedingungen, die im Vorfeld der Westküste herrschten, bevor der Kniepsand an die Insel heranwanderte. Die geologische Ausgangssituation stellt der leicht nach Westen abfallende Inselgeestkern bestehend aus Endmoränenrelikten der Saale-Eiszeit dar. Von Westen aus folgte eine Anlagerung rein mariner Sedimente (coastal onlap).

Auf der Landoberfläche des ertrinkenden Geestkern wurden zu Beginn der Transgression feinkörnige Sedimente eines Misch- bis Schlickwatts abgelagert.

Diese zeugen von Stillwassersedimentation und ruhigeren Strömungsbedingungen als diese heute an der hochenergetischen Westküste Amrums herrschen. Es ist davon auszugehen, dass der damals noch weit vor der Küste Amrums liegende Kniepsand eine Barriere bildete und so an der Westküste für strömungsberuhigte Sedimentationsbedingungen sorgte. Der Transgressionskontakt konnte mit Hilfe einer mittels der AAR-Methode auf 2122 +/-54 Jahren datierten Muschelschale der Gattung Cerastoderma edule bestimmt werden. In Übereinstimmung mit FALK (2001) wurde das Gebiet der Westküste Amrums zunehmend an der Grenze zwischen Subboreal und einsetzendem Subatlantikum von der Transgression erreicht.

Im Hangenden des Westküstenwatts folgten Ablagerungen eines Strandes, der eine ausgeprägte ridge-and-runnelTopographie aufgrund von zahlreichen in das Strandpro- 
fil eingeschalteten intertidalen Sedimentkörpern aufweist. Durch Sturmfluterosion am Geestkern konnten sich Brandungshohlkehlen ausbilden, die zur Kliffbildung führten. Fossile Kliffs in unterschiedlichen Höhenpositionen lassen auf unterschiedliche Meeresspiegelniveaus schließen.

Das zweite Modell beschreibt die Migration und den Andockmechanismus des der Insel im Westen vorgelagerten Kniepsandes an Amrum. Es erfolgte eine strömungsbedingte Anlagerung von Sedimenten an die „Stirn“ des Kniepsandkörpers. Dies führte allmählich zur Progradation und zum Heranwandern des Kniepsandes an die Insel. Dabei schob sich der Kniepsand zum Teil auf die zuvor an der Westküste Amrums abgelagerten, stratigraphisch älteren Strand- und Vorstrandsedimente hinauf. Die einstige Andockstelle befindet im Vergleich zu heute etwa $200 \mathrm{~m}$ weiter im Nordosten. Eine Anlagerung des Kniepsandes an die Insel wird für die Zeitspanne zwischen 1648 und 1841 angenommen.

Mit dem Trockenfallen der entstandenen Sandflächen nach Ende der Transgression wurden die Bedingungen für die anschließende großflächige Dünenbildung geschaffen, die durch den Sedimentinput aus dem Kniepsand zunehmend generiert werden konnten. Mit fortschreitender Dünenbildung wurde das Geestkliff vor der Brandung und vor fortschreitender Abrasion geschützt und entwickelte sich allmählich zum toten Kliff.

\section{Danksagung}

Ein besonderer Dank geht an die Deutsche Bundesstiftung Umwelt (DBU) für die finanzielle Unterstützung durch ein Promotionsstipendium. Ferner danken wir den Freunden und Förderern der Goethe-Universität, der FAZIT-Stiftung, der Hermann Willkomm Stiftung, der GEOPRAX Projektförderung, dem AK Geomorphologie sowie dem DAAD für die Bereitstellung von Sach- und Reisekosten. Für die Genehmigungen für unsere Arbeiten im Gelände bedanken wir uns beim Amt für Kreisentwicklung, Bau und Umwelt/ Untere Naturschutzbehörde in Husum. Dem GEORADARFORUM sowie Herrn Prof. Dr. Andreas Junge (Goethe-Universität Frankfurt/ Institut für Angewandte Geophysik) sei herzlich für die Bereitstellung des benötigten GPR-Equipments gedankt. Ferner danken wir zwei anonymen Gutachtern für das Verfassen der Reviews, die uns halfen das Manuskript zu verbessern.

\section{Literatur}

Allen, J. R. L. (1982): Sedimentary structures: their character and physical basis. Vol. 1, Developments in sedimentology, Vol. 30 A. - 593 p.; Amsterdam (Elsevier).

Annan, A. P. (2001): Ground Penetrating Radar - Workshop Notes. Sensors and Software Inc., Ontario, Kanada.

Annan, A. P. (2009): Electromagnetic Principles of Ground Penetrating Radar. - In: Jol, H. M. (ed.): Ground Penetrating Radar: Theory and Applications: 3-40; Amsterdam (Elsevier).

Blindow, N., Richter, T. \& Petzold, H. (2005): Bodenradar. - In: Knödel, K., Krümmel, H. \& Lange, G. (eds.): Handbuch zur Erkundung des Untergrundes von Deponien und Altlasten Band 3: Geophysik: 389424; Berlin (Springer).

Blott, S. J. \& Pye, K. (2001): Gradistat: A grain size distribution and statistics package for the analyses of unconsolidated sediments. - Earth Surface Processes and Landforms, 26: 1237-1248.

Botha, G. A., Bristow, C. S., Porat, N., Duller, G., Armitage, S. J., Roberts, H. M., Clarke, B. M., Kota, M. W. $\mho$ Schoeman, P. (2003): Evi- dence for dune reactivation from GPR profiles on the Maputaland coastal plain, South Africa. - In: BRIstow, C. S. \& Jol, H. M. (eds.) Ground penetrating radar in sediments. - Geological Society, London, Special Publications, 211. Brassmill Lane: 29-46.

BRIstow, C. S. (2009): Ground penetrating radar in aeolian dune sands - In: Jol, H. M. (ed.): Ground Penetrating Radar: Theory and Applications: 273-297; Oxford (Elsevier).

Bristow, C. S., Augustinus, P. C., Wallis, I. C., Jol, H. M. ひ Rhodes, E. J. (2010a): Investigation of the age and migration of reversing dunes in Antarctica using GPR and OSL, with implications for GPR on Mars. Earth and Planetary Science Letters, 289: 30-42.

Bristow, C. S., Bailey, S. D. \& Lancaster, N. (2000a): The sedimentary structure of linear sand dunes. - Nature, 406: 56-59.

Bristow, C. S., Chroston, P. N. \& Bailey, S. D. (2000b): The structure and development of foredunes on a locally prograding coast: insights from ground-penetrating radar surveys, Norfolk, UK. - Sedimentology, 47 (5): 923-944.

Bristow, C. S., Jol, H. M., Augustinus, P. \& Wallis, I. (2010b): Slipface whaleback dunes in a polar desert, Victoria Valley, Antarctica: Insights from ground penetrating radar. - Geomorphology, 114: 361-372.

BRIstow, C. S. \& Pucillo, K. (2006): Quantifying rates of coastal progradation from sediment volume using GPR and OSL: the Holocene fill of Guichen Bay, south-east South Australia. - Sedimentology, 53 (4): 769-788.

Bristow, C. S., Pugh, J. \& Goodall, T. (1996): Internal structure of aeolian dunes in Abu Dhabi determined using ground-penetrating radar. Sedimentology, 43 (6): 995-1003.

CAmpBell, C. V. (1967): Lamina, laminaset, bed and bedset. - Sedimentology, 8: 7-26.

CAtunEanu, O. (2002): Sequence stratigraphy of clastic systems: concepts, merits, and pitfalls. - Journal of African Earth Sciences, 35: 1-43.

DAnckwerth, C. D. (1652): Die Landkarten des Johann Mejer, Husum, aus der neuen Landschaftsbeschreibung der zwei Herzogtümer Schleswig und Holstein von Casper David Danckwerth 1652, Hamburg-Bergedorf 1963 (Reprint).

DAvis, R. A. (1992): Depositional Systems: an introduction to Sedimentology and Stratigraphie. - Prentice Hall, Englewood Cliffs, New Jersey: $591 \mathrm{p}$.

Demarchi, B., Williams, M. G., Milner, N., Russell, N., Bailey, G. \& Penkman, K. (2011): Amino acid racemization dating of marine shells a mound of possibilities. - Quaternary International, 239: 114-124.

EMERy, D. \& MYers, K. (1996): Sequence Stratigraphy. - 297 p.; Oxford (Blackwell Science Ltd).

FALK, G. C. (2001): Die Paläogeomorphologie ausgewählter Standorte der schleswig-holsteinischen Nordseeküste im Früh- und Mittelholozän. - Dissertation, Universität Berlin: $171 \mathrm{~S}$.

Fisher, S. C., STEwARD, R. R. \& Jol, H. M. (1996): Ground-penetrating radar (GPR) data enhancement using seismic techniques. - Journal of Environmental Engineering \& Geophysics, 1: 89-96.

FitzGerald, D. M. (2005): Tidal Inlets. - In: Schwartz, M. L. (ed.): Encyclopedia of Coastal Science: 958-965; (Springer).

FolK, R. L. \& WARD, W. C. (1957): Brazos River bar (Texas): a study in the significance of grain size parameters. - Journal of Sedimentary Petrology, 27: 3-26.

Girardi, J. D. \& Davis, D. M. (2010): Parabolic dune reactivation and migration at Napeague, NY, USA: Insights from aerial and GPR imagery. - Geomorphology, 114: 530-541.

Goodfriend, G. A. (1987): Chronostratigraphic studies of sediments in the Negev Desert, using amino acid epimerization analysis of land snail shells. - Quaternary Research, 28: 374-392.

Gray, J. S. \& Elliott, M. (2009): Ecology of marine sediments: from science to management. - 225 p.; Oxford, New York (Oxford University Press).

GreENwood, B. (2005): Bars. - In: Schwartz, M. L. (ed.): Encyclopedia of Coastal Science: 120-129; (Springer).

GRIPP, K. (1968): Zur jüngsten Erdgeschichte von Hörnum / Sylt und Amrum mit einer Übersicht über die Entstehung der Dünen in Nordfriesland. - Die Küste, 16: 76-117.

HANsen, C. P. (1845): Die Insel Sylt in geschichtlicher und statistischer Hinsicht. - Langhoffsche Buchdruckerei, $203 \mathrm{~S}$.

Hanssen, G. (1835): Statistische Mitteilungen über nordfriesische Distrikte. - Neues Staatsbürgerliches Magazin, Bd. 3, Schleswig.

HARARI, Z. (1996): Ground-penetrating radar (GPR) for imaging stratigraphic features and groundwater in sand dunes. - Journal of Applied Geophysics, 36: 43-52.

Hassenpluug, W. (1985): Die Vielfalt der Küstenfomen im Überblick. - In Hassenpflug, W., Kortum, G., Newig, J., Pollex, W., \& Schmidtke, 
K. (eds.): An Nord- und Ostsee. Schleswig-Holsteins Küsten: 7-47; Husum (Husum Druck- und Verlagsgesellschaft).

HAYEs, M. O. (1980): General morphology and sediment patterns in tidal inlets. - Sedimentary Geology, 26: 139-156.

Jackson, D. W. T., Anfuso, G. ש Lynch, K. (2007): Swash bar dynamics on a high-energy mesotidal beach. - Journal of Coastal Research, 50: 738-745.

Jakobsen, P. \& OvergaARD, T. (2002): Georadar facies and glaciotectonic structures in ice marginal deposits, northwest Zealand, Denmark. Quaternary Science Reviews, 21: 917-927.

JohANNSEN, C. (1861): Die Insel Amrum. - In: Jahrbuch für die Landeskunde Schleswig-Holstein, Bd. 4, Schleswig.

Johannsen, C. (1867): Das Westschleswigsche Küstenland im 13. und 14 Jahrhundert und die Johann Meyer'schen Karten des alten Nordfrieslands vom Jahre 1240. - Schleswig.

JoL, H. M. ¿ BRISTOw, C. S. (2003): GPR in sediments: advice on data collection, basic processing and interpretation, a good practice guide. - In: BRISTow, C.S. \& JoL, H. M. (eds.): Ground penetrating radar in sediments. Geological Society, London, Special Publications, 211, pp. 9-27.

JoL, H. M. \& SмIтн, D. G. (1991): Ground-penetrating radar of northern lacustrine deltas. - Canadian Journal of Earth Sciences, 28: 1939-1947.

Jessen, O. (1914): Morphologische Beobachtungen an den Dünen von Amrum, Sylt und Röm. - Landeskundliche Forschungen 21.

Jessen, O. (1932): Die postdiluviale Entwicklung Amrums und seine subfossilen und rezenten Muschelpflaster. - In: Jahrbuch der Preuß. Geolog. Landesanstalt zu Berlin, 53: 1-69.

Kersten, K. (1969): Die Vorzeit der Insel Amrum. - In: Hansen, M. o Hansen, N. (eds.): Amrum: Geschichte und Gestalt einer Insel: 7-11; Itzehoe-Münsterdorf (Hansen \& Hansen).

KösTER, R. (1998):Wattsedimente. - In: Umweltatlas Wattenmeer, Band 1: Nordfriesisches und Dithmarscher Wattenmeer. - 270 S.; Stuttgart (Eugen Ulmer).

Krause, A. (1913): Die Insel Amrum: Eine Landeskunde. - In: Ule, W. (eds.): Geographische Arbeiten. - 88 S.; Stuttgart (Strecker \& Schröder).

LANG, A. W. (1973): Historisches Seekartenwerk der Deutschen Bucht. Neumünster (Wachholtz)

McKeE, E. D. ש WeIR, G. W. (1953): Terminology for stratification and crossstratification in sedimentary rocks. - Bull. Geol. Soc. Am., 64: 381-390.

MeIER, O. G. (1987): Die Naturschutzgebiete auf Sylt und Amrum. - 147 S.; Heide, Holstein (Boyens \& Co)

MeYn, L. (1876): Geognostische Beschreibung der Insel Sylt und ihrer Umgebung. - Abhandlungen zur geologischen Spezialkarte von Preußen I (4), Berlin, $74 \mathrm{~S}$

MiALL, A. D. (1991): Hierarchies of architectural units in terrigenous clastic rocks, and their relationship to sedimentation rate. In: MiALL, A. D. and TAYler, N., (eds.): The tree-dimensional facies architecture of terrigenous clastic sediments and its implications for hydrocarbon discovery and recovery. Concepts in Sedimentology and Palaeontology, Vol. 3. Tulsa, OK., SEPM: pp. 6-12.

Mitchum, R. M., VAIL, P. R. \& SANGREe, J. B. (1977): Stratigraphic interpretation of seismic reflection patterns in depositional sequences. - In: PAyton, C. E. (ed.): Seismic stratigraphy: applications to Hydrocarbon Exploration. AAPG Mem. 16: 117-123.

MÜLLER \& FISCHER (1937): Amrum. Das Wasserwesen an der schleswigholsteinischen Nordseeküste. - Teil II: Die Inseln, Band 5. - 237 S. Berlin (Dietrich Reimer).

Murray-Wallace, C. V. ひ Belperio, A. P. (1994): Identification of remanié fossils using amino acid racemisation. - Alcheringa, 18: 219-227.

NEAL, A. (2004): Ground-penetrating radar and its use in sedimentology: principles, problems and progress. - Earth-Science Reviews, 66: 261330

Отт, J. (1996): Meereskunde: Einführung in die Geographie und Biologie der Ozeane. - 2. Aufl. 424 S.; Stuttgart (UTB).

PaYton, C. E. (1977): Seismic Stratigraphy - Applications of Hydrocarbon Exploration, American Association of Petroleum Geologists, Tulsa, Oklahoma, Memories. 16
Pedersen, K. \& Clemmensen, L. B. (2005): Unveiling past aeolian landscapes: A ground penetrating radar survey of a Holocene coastal dunefield system, Thy, Denmark. - Sedimentary Geology, 177: 57 -86.

Pотт, R. (2003): Die Nordsee: Eine Natur- und Kulturgeschichte. -339 S.; München (C. H. Beck).

Quedens, G. (2008): Amrum. 23. Aufl. - 144 S. (Breklumer Verlag)

Remde, F. (1972): Amrum. Ein Beitrag zur Genese und Struktur einer Inselsiedlung. Dissertation, Wilhelms-Universität, Münster: $181 \mathrm{~S}$.

SchÄFER, A. (2005): Klastische Sedimente. Fazies und Sequenzstratigraphie 1. Aufl. 414 S.; München (Elsevier/ Spektrum).

Schwartz, M. L. (2005): Encyclopedia of Coastal Science. - 1211 p.; Dordrecht (Springer).

Sindowski, K.-H. (1973): Das ostfriesische Küstengebiet: Inseln, Watten und Marschen.- Sammlung Geologischer Führer 57. - 162 S.; Berlin, Stuttgart (Borntraeger).

Sindowski, K.-H. (1979): Zwischen Jadebusen und Unterelbe. - Sammlung Geologischer Führer 66. - 145 S.; Berlin, Stuttgart (Borntraeger).

Sommer, U. (2005): Biologische Meereskunde. - 2. Aufl. - 412 S.; Berlin, Heidelberg (Springer).

StoLt, R. H. (1978): Migration by Fourier transform. - Geophysics, 43: 2348.

TANNER, W. F. (1995): Origin of beach ridges and swales. - Marine Geology, 129: $149-161$.

Tillmann, T. \& Wunderlich, J. (2011a): Facies and Development of a Holocene Barrier Spit (Southern Sylt/ German North Sea). Proceedings of the $6^{\text {th }}$ International Workshop on Advanced Ground Penetrating Radar (IWAGPR 2011 June 22-24, 2011, Aachen, Germany): pp. 188-194.

Tillmann, T. \& Wunderlich, J. (2011b): Genese eines Strandhakens am Beispiel der Hörnum-Odde (Süd-Sylt): Untersuchungen des oberflächennahen Untergrundes durch die Kombination von geophysikalischen und sedimentologischen Methoden. In: Karius, V., HAdLer, H., Deicke, M., von Eynatten, H., Brückner, H. \& Vött, A. (eds.) Dynamische Küsten: Grundlagen, Zusammenhänge und Auswirkungen im Spiegel angewandter Küstenforschung. - Coastline Reports, 17: $177-190$.

TillmanN, T. ש WUNDERLich, J. (2012): Ground-penetrating radar in coastal environments: Examples from the islands Sylt and Amrum. - Bremer Beiträge zur Geographie und Raumplanung, 44: 60-76.

Tillmann, T. \& Wunderlich, J. (2013): Barrier rollover and spit accretion due to the combined action of storm surge induced washover events and progradation: Insights from ground-penetrating radar surveys and sedimentological data. - Journal of Coastal Research, Special Issue No 65 (1): 600-605.

TuCKER, M. E: (1985): Einführung in die Sedimentpetrologie. - 265 S.; Stuttgart (Enke).

VAN DAM, R. L. (2012): Landform characterization using geophysics - recent advances, applications, and emerging tools. - Geomorphology, 137 (1) $57-73$

VAN OverMEeren, R. A. (1998): Radar facies of unconsolidated sediments in The Netherlands: a radar stratigraphy interpretation method for hydrogeology. - Journal of Applied Geophysics, 40: 1-18.

Voigt, H. (1969): Die Insel Amrum: Landschaft und Entwicklung. - In HANSEN, M. \& HANSEN N. (eds.): Sylt: Geschichte und Gestalt einer Insel: 11-34; Itzehoe (Hansen \& Hansen).

Zausig, F. (1939): Veränderungen der Küsten, Sände, Tiefs und Watten de Gewässer um Sylt (Nordsee) nach alten Seekarten, Seehandbüchern und Landkarten seit 1585. - Geologie der Meere und Binnengewässer, $3(4): 401-505$.

ZIEHE, D. (2009): Aminosäure-D/L-Verhältnisse in biogenem Carbonaten als Schlüssel zur Datierung holozäner Sedimentationsvorgänge im norddeutschen Küstenraum. - Dissertation, Carl von Ossietzky Universität Oldenburg: $219 \mathrm{~S}$. 